\title{
Variable Impact of COVID-19 Lockdown on Air Quality across 91 Indian Cities $\mathscr{}$
}

\author{
Ansar Khan, ${ }^{\mathrm{a}}$ Samiran Khorat, ${ }^{\mathrm{b}}$ Rupali Khatun, ${ }^{\mathrm{c}}$ QuAng-VAN DoAn, ${ }^{\mathrm{d}}$ U. S. NAIR, ${ }^{\mathrm{e}}$ AND DeV NiYOGi ${ }^{\mathrm{f}, \mathrm{g}}$

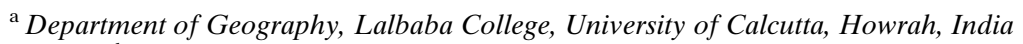 \\ ${ }^{\mathrm{b}}$ Department of Geography, University of Calcutta, Kolkata, India \\ ${ }^{\mathrm{c}}$ School of Oceanographic Studies, Jadavpur University, Kolkata, India \\ ${ }^{\mathrm{d}}$ Centre for Computational Sciences, University of Tsukuba, Ibaraki, Japan \\ e Department of Atmospheric Sciences, University of Alabama in Huntsville, Huntsville, Alabama \\ ${ }^{\mathrm{f}}$ Department of Geological Sciences, Jackson School of Geosciences, The University of Texas at Austin, Austin, Texas \\ ${ }^{\mathrm{g}}$ Department of Civil, Architectural, and Environmental Engineering, The University of Texas at Austin, Austin, Texas
}

(Manuscript received 22 September 2020, in final form 1 April 2021)

\begin{abstract}
India responded to the severe acute respiratory syndrome (SARS) coronavirus disease 2019 (COVID-19) pandemic through a three-phase nationwide lockdown: 25 March-14 April, 15 April-3 May, and 4-17 May 2020. We utilized this unique opportunity to assess the impact of restrictions on the air quality of Indian cities. We conducted comprehensive statistical assessments for the air quality index (AQI) and criteria pollutant concentrations for 91 cities during the lockdown phases relative to the preceding seven days (prelockdown phase of 18-24 March 2020) and to corresponding values from the same days of the year in 2019. Both comparisons show statistically significant countrywide mean decrease in AQI (33\%), $\mathrm{PM}_{2.5}(36 \%), \mathrm{PM}_{10}(40 \%), \mathrm{NO}_{2}(58 \%), \mathrm{O}_{3}(5 \%), \mathrm{SO}_{2}(25 \%), \mathrm{NH}_{3}(28 \%)$, and $\mathrm{CO}(60 \%)$. These reductions represent a background or the lower bound of air quality burden of industrial and transportation sectors. The northern region was most impacted by the first two phases of the lockdown, whereas the southern region was most affected in the last phase. The northeastern region was least affected, followed by the eastern region, which also showed an increase in $\mathrm{O}_{3}$ during the lockdown. Analysis of satellite-retrieved aerosol optical depth (AOD) shows that effects of restrictions on particulate pollution were variable-locally confined in some areas or having a broader impact in other regions. Anomalous behavior over the eastern region suggests a differing role of regional societal response or meteorological conditions. The study results have policy implications because they provide the observational background values for the industrial and transportation sector's contribution to urban pollution.
\end{abstract}

KEYWORDS: Aerosol optical properties; Aerosols/particulates; Air pollution; Urban meteorology

\section{Introduction}

India is home to about one-half of the world's 20 most polluted cities, with emissions fueled by industry, vehicle exhaust, and power plants owing to the fast-paced development through the 1990s (Ghude et al. 2016; Garaga et al. 2018). India's toxic air claimed 1.24 million deaths in 2017 , accounting for nearly $12.5 \%$ of the total deaths. Of these fatalities, approximately 0.67 million have been attributed to ambient particulate matter and 0.48 million are from household air pollution (Balakrishnan et al. 2019). As a result, Indian cities are important locales for understanding the complex relationship between human activity and air pollution.

The inadvertent, worldwide modification of anthropogenic activity caused by restrictions imposed to combat the spread of severe acute respiratory syndrome (SARS) coronavirus disease 2019 (COVID-19) was particularly noteworthy in India. As a

Supplemental information related to this paper is available at the Journals Online website: https://doi.org/10.1175/EI-D-20-0017.s1.

Corresponding author: Ansar Khan, khanansargeo@gmail.com

Earth Interactions is published jointly by the American Meteorological Society, the American Geophysical Union, and the Association of American Geographers. background, following the reports of the first cases of pneumonia associated with COVID-19 on 31 December 2019 in Wuhan, China, the World Health Organization (WHO) declared COVID-19 a Public Health Emergency of International Concern on 31 January. The first case of COVID-19 in India was reported on 30 January 2020 in Thrissur, Kerala, for an individual who had traveled back from China. Within a few weeks, India experienced a jump in COVID-19 confirmed cases crossing 100. The WHO declared the COVID-19 outbreak a pandemic on 12 March 2020. In response, the government of India (GoI) initiated on 22 March a 14-h voluntary public curfew. This was followed by a complete lockdown of major cities and districts where COVID-19 cases were detected. The outbreak was subsequently declared an epidemic in more than a dozen states and union territories, and the provisions of the Epidemic Diseases Act (1897) were invoked. On 24 March, the GoI ordered a nationwide phase-I lockdown for 21 days, impacting India's entire 1.3 billion population. On 14 April, the lockdown was extended for phase II until 3 May 2020 and was further extended from 4 to 17 May as phase III of the lockdown. During each lockdown, some relaxations or changes in rules were established, adapting to the local and regional situation (Lancet 2020).

The restrictions on social distancing and self-quarantine measures enforced during the three-phase lockdown caused reduced emissions from industrial sources, vehicle exhaust, and coal-fired power plants throughout the country. This study utilized the COVID-19 restrictions as a social experiment to 
analyze the impact of human activity on the air quality of 91 Indian cities (Table S1 in the online supplemental material). Air quality across the different cities was examined for the following days in 2020: 1) prelockdown = 7 days (18-24 March), 2) lockdown phase $\mathrm{I}=21$ days (25 March-14 April), 3) lockdown phase II = 19 days (15 April-3 May), and 4) lockdown phase III = 14 days (4-17 May). The air quality for the corresponding days in the preceding year (2019) was used as a reference to analyze the impact of COVID-19 lockdown on urban air quality across India in this premonsoon period.

\section{Materials and methods}

We utilized the daily mean values of air quality index (AQI) and concentrations of seven criteria air pollutants $\left(\mathrm{PM}_{2.5}\right.$, $\mathrm{PM}_{10}, \mathrm{O}_{3}, \mathrm{SO}_{2}, \mathrm{NO}_{2}, \mathrm{NH}_{3}$, and $\mathrm{CO}$ ) from 91 cities (Fig. 1). The time of interest for this study is from 18 March to 17 May 2020, and the corresponding days of 2019. We also used satellite retrievals of aerosol optical depth (AOD) to give a larger spatial perspective than can be provided by in situ observations. In addition to countrywide analysis, we also conducted a case study for the Kolkata-Howrah region to explore more-detailed synergies between pandemic lockdown and air quality.

\section{a. In situ and satellite observations of air quality}

Air quality monitoring is an integral part of air quality risk management nationwide. In this regard, the National Air Monitoring Program (NAMP) was set up by the Central Pollution Control Board (CPCB 2014) to measure the status of air quality, spatiotemporal trends and to control and regulate pollutants from different sources to meet the air quality standards in cities across India. As part of this monitoring, continuous monitoring systems that provide data on a nearreal-time basis are installed in a number of cities. Data for 91 cities were extracted from the CPCB portal for 1) AQI bulletin (https://cpcb.nic.in/AQI_Bulletin.php) and 2) air pollutants and meteorological data (https://app.cpcbccr.com/ccr/\#/caaqmdashboard/caaqm-landing). The daily concentrations of seven criteria pollutants were used for each lockdown phase. The AQI captures various air pollutants for which national air quality standards have been established to safeguard public health. There are six AQI categories, namely, good (0-50), satisfactory (51-100), moderately polluted (101-200), poor (201-300), very poor (301-400), and severe (401-500). Also, derived level-3 AOD from a Moderate Resolution Imaging Spectroradiometer (MODIS) aboard Terra was used for the analysis. The MODIS AOD fields were used for a twin comparison of urban versus nonurban locales to assess the background and the urban changes.

\section{b. Considering missing air pollution data}

Some of the statistical analysis methods utilized are not amenable to missing observations, which is a prevalent problem in air quality studies (Hadeed et al. 2020). Missing in situ air pollution observations can result from malfunctions and errors, power outages, computer system crashes, pollutant levels lower than detection limits, and filter changes (Imtiaz and Shah 2008; Li et al. 2007). Prior studies have identified three different types of missing data scenarios in air pollution studies, namely, missing completely at random (MCAR), missing at random (MAR), and not missing at random (NMAR) (Little and Rubin 2002; Schafer 1999). The MAR criterion was found for $7 \%$ of missing data found in the datasets used in this study.

We utilized a regression method for estimating missing values. A regression model was fitted for each criterion air pollutant missing values, with the air pollutant as covariates (Taghavi-Shahri et al. 2020). Since the dataset has a monotone missing data pattern, the process is repeated sequentially for pollutants with missing values (Yuan 2016) as

$$
Y_{j}=\beta_{0}+\beta_{1} Y_{1}+\beta_{2} Y_{2}+\cdots+\beta_{(j-1)} Y_{(j-1)}
$$

That is, for a pollutant $Y_{j}$ with missing values, a regression model is fitted with the adjacent nonmissing cities (stations).

The fitted model has the regression parameter estimates $\hat{\beta}_{0}, \hat{\beta}_{1}, \ldots, \hat{\beta}_{j-1}$ and the associated covariance matrix $\sigma_{1}^{2} \mathbf{V}_{J}$, where $\mathbf{V}_{J}$ is the usual $\mathbf{X}^{\prime} \mathbf{X}$ matrix from the intercept and pollutants $Y_{1}, Y_{2}, \ldots, Y_{J-1}$. For each imputation, new parameters $\beta_{0}, \beta_{1}, \ldots, \beta_{j-1}$ and $\sigma_{j}^{2}$ are drawn from the posterior predictive distribution of the missing data. That is, they are computed from $\hat{\beta}_{0}, \hat{\beta}_{1}, \ldots, \hat{\beta}_{j-1}, \sigma_{1}^{2}$, and $\mathbf{V}_{J}$.

Then missing values are replaced by

$$
\beta_{0}+\beta_{1} y_{1}+\beta_{2} y_{2}+\cdots+\beta_{(j-1)} y_{(j-1)}+z_{i} \sigma_{j}
$$

where $y_{1}, y_{2}, \ldots, y_{(j-1)}$ are the covariate values of the first $j-1$ pollutants and $z_{i}$ is a calculated normal deviate. The above regression model was employed to fill in the missing data for air quality datasets utilized in the study.

\section{c. Bivariate correlation $(B C)$ and test}

We utilize a simple correlation of AQI between 2019 and 2020 for the days of the year corresponding to prelockdown through lockdown phase III (Liu et al. 2019; Kumar et al. 2020). A correlation coefficient is used to determine the strength and direction of association of AQI between the two years. Positive and negative correlations indicate similar and opposing temporal trends between 2019 and 2020, respectively, while the magnitude of the correlation indicates the strength of this association. Statistical significance of the correlation was also determined using the $t$ test. Denoting AQI for any given day of 2019 and 2020 as $\mathrm{AQI}_{i}$ and $\mathrm{AQI}_{i}{ }^{\prime}$, respectively, correlation coefficient $r$ is defined as

$$
\frac{\sum_{i=1}^{N}\left[\left(\mathrm{AQI}_{i}-\overline{\mathrm{AQI}}\right)\left(\mathrm{AQI}_{i}^{\prime}-\overline{\mathrm{AQI}^{\prime}}\right)\right]}{\sqrt{\sum_{i=1}^{N}\left(\mathrm{AQI}_{i}-\overline{\mathrm{AQI}}\right) \sum_{i=1}^{N}\left(\mathrm{AQI}_{i}^{\prime}-\overline{\mathrm{AQI}^{\prime}}\right)}}=-1 \leq r \leq 1
$$

where $N$ is the number of observations and the overbar indicates the mean of the variable for the timeframe applicable. To test whether the association is merely apparent and might have arisen by chance, we use the $t$ test (two tailed) with $p \leq 0.05$ as

$$
t=r \sqrt{\frac{n-2}{1-r^{2}}} .
$$




\section{d. Detection of the trend; magnitude of the slope}

\section{1) MK TEST}

The Mann-Kendall (MK) test is the rank-based nonparametric test to detect trends in environmental data (e.g., Emami et al. 2018). It is based on the test statistic $S$ defined as

$$
S=\sum_{i=1}^{n-1} \sum_{j=i+1}^{n} \operatorname{sgn}\left(x_{j}-x_{i}\right)
$$

where $x_{1}, x_{2}, \ldots, x_{n}$ represent $n$ data points and $x_{j}$ represent the data point at the time $j$.

An $S$ with high positive value is an indicator of an increasing trend, and a low negative value indicates a decreasing trend:

$$
\operatorname{sgn}\left(x_{j}-x_{i}\right)\left\{\begin{array}{l}
\operatorname{for}\left(x_{j}-x_{i}\right)>1 \\
\operatorname{for}\left(x_{j}-x_{i}\right)=0 \\
\operatorname{for}\left(x_{j}-x_{i}\right)<1
\end{array}\right\} .
$$

When $n \geq 10$, the statistic $S$ is approximately normally distributed with the mean

$$
E(S)=0,
$$

and its variance is

$$
\operatorname{Var}(S)=\frac{n(n-1)(2 n+5)-\sum_{i=1}^{m} t_{i}\left(t_{i}-1\right)\left(2 t_{i}+5\right)}{18},
$$

where $n$ is the number of data points, $m$ is the number of tied groups (a tied group is a set of sample data having the same value), and $t_{i}$ is the number of data points in the $i$ th group. The standardized test statistic $Z$ is computed as follows:

$$
Z=\left\{\begin{array}{cc}
\frac{S-1}{\sqrt{\operatorname{Var}(S)}} & \text { if } S>0 \\
0 & \text { if } S=0 \\
\frac{S+1}{\sqrt{\operatorname{Var}(S)}} & \text { if } S<0
\end{array}\right\} .
$$

The null hypothesis $H_{0}$, meaning that no significant trend is present, is accepted if the test statistic $Z$ is not statistically significant, that is, $-Z_{\alpha / 2}<Z<Z_{\alpha / 2}$, where $Z_{\alpha / 2}$ is the standard normal deviate.

\section{2) TSE}

The slope of $n$ pairs of data points was estimated using the Theil-Sen estimator (TSE; Theil 1950; Sen 1968), which is given by the following relation:

$$
T_{i}=\frac{x_{j}-x_{i}}{j-i},
$$

where $x_{j}$ and $x_{i}$ present as data values at a time $j$ and $i(j>1)$, respectively. The median of the $N$ values $T_{i}$ is considered as Sen's estimator of the slope, which is calculated by the formula

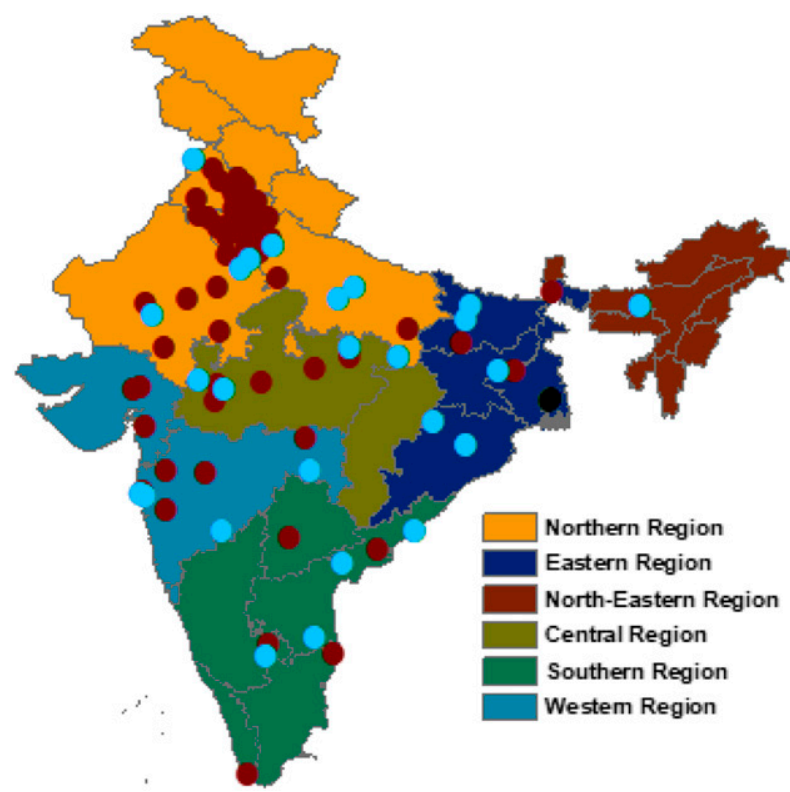

FIG. 1. Locations of the 91 air quality observation sites used in the study (filled circles). Of these, 27 locations (shown using blue and black circles) are chosen for additional analysis on the basis of statistically significant trends. Major geographical regions within the Indian subcontinent (and referred to in the main text) are highlighted using different colors, with the associated descriptions being provided in the map legend.

$$
Q_{i}=\left\{\begin{array}{cc}
\frac{T_{N+1}}{2} & N=\text { odd } \\
\frac{1}{2}\left(\frac{T_{N}}{2}+\frac{T_{N+2}}{2}\right) & N=\text { even }
\end{array}\right\} .
$$

The positive value $Q_{i}$ indicates an increasing trend, and a negative value $Q_{i}$ indicates a decreasing trend in the time series (Xu et al. 2010), while its value indicates the steepness of the trend. To determine whether the median slope is statistically different from zero, the confidence interval of $Q_{i}$ a specific probability is estimated.

The confidence interval about the time slope (Hollander and Wolfe 1973; Gilbert 1987) can be computed as follows:

$$
C_{\alpha}=Z_{1-\alpha / 2 \sqrt{\operatorname{Var}(S)}}
$$

In this study, the confidence interval was computed at the 0.05 significance level $(\alpha=0.05)$. Then, $M_{1}=\left(N-C_{\alpha}\right) / 2$ and $M_{2}=$ $\left(N+C_{\alpha}\right) / 2$ are computed. The lower and upper limits of the confidence interval $Q_{\min }$ and $Q_{\max }$ are the $M_{1}$ th largest and the $\left(M_{2}+1\right)$ th largest of the $N$ ordered slope estimates (Gilbert 1987). The slope $Q_{i}$ is statistically different from zero if the two limits $\left(Q_{\min }, Q_{\max }\right)$ have a similar sign. Sen's slope estimator has been widely used in air pollutant time series (e.g., Ravindra et al. 2020; Gray et al. 2019; Emami et al. 2018; Lang et al. 2019).

\section{e. VR analysis}

The principal component analysis (PCA) is a multivariate statistical tool used for reducing the dimensionality 


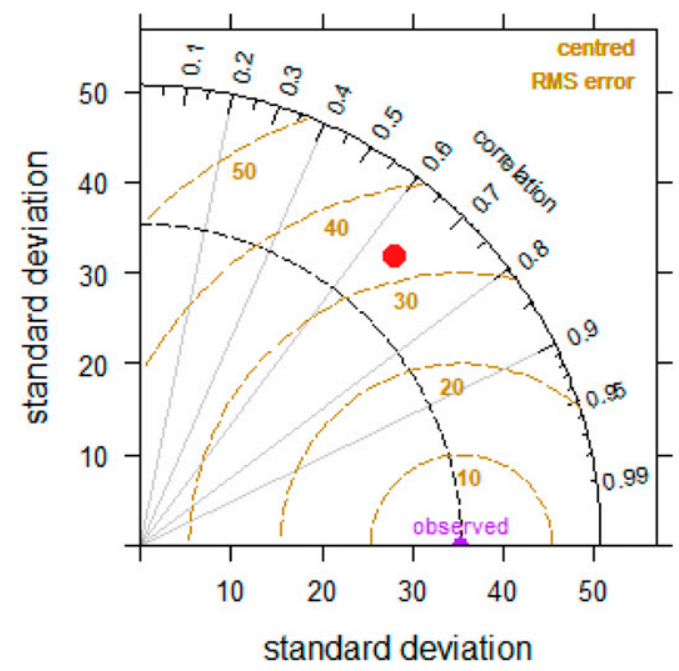

(a)

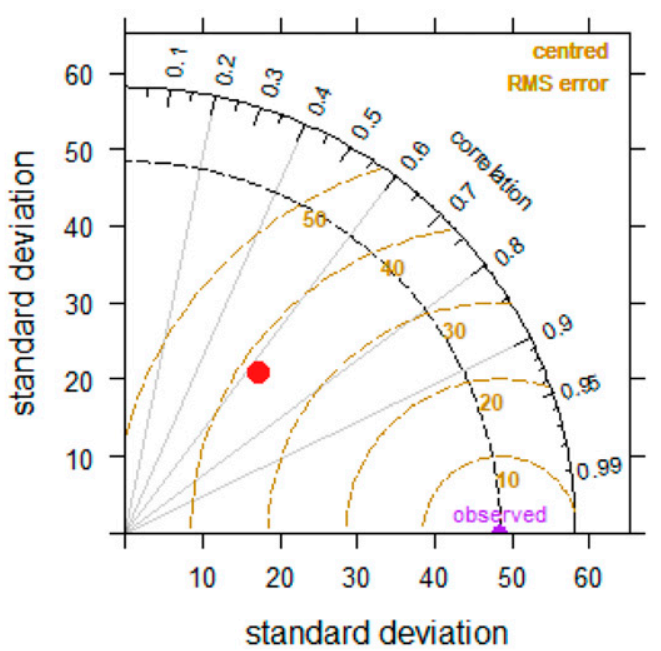

(b)

FIG. 2. Taylor diagram for the AQI data during the (a) prelockdown period (2019 vs 2020) and (b) lockdown period (2019 vs 2020).

of a dataset involving a large number of interrelated pollutants. The change of coordinates used in PCA is known as varimax rotation (VR). The VR method (Kaiser 1958) is a widely used orthogonal tool to separate subregions of homogenous air pollutant concentrations (Parveen and Ahmad 2020; Chen and Bloom 2019). The VR method attempts to retain the maximum $Q$ value ( $\mathrm{Yu}$ and Chang 2000):
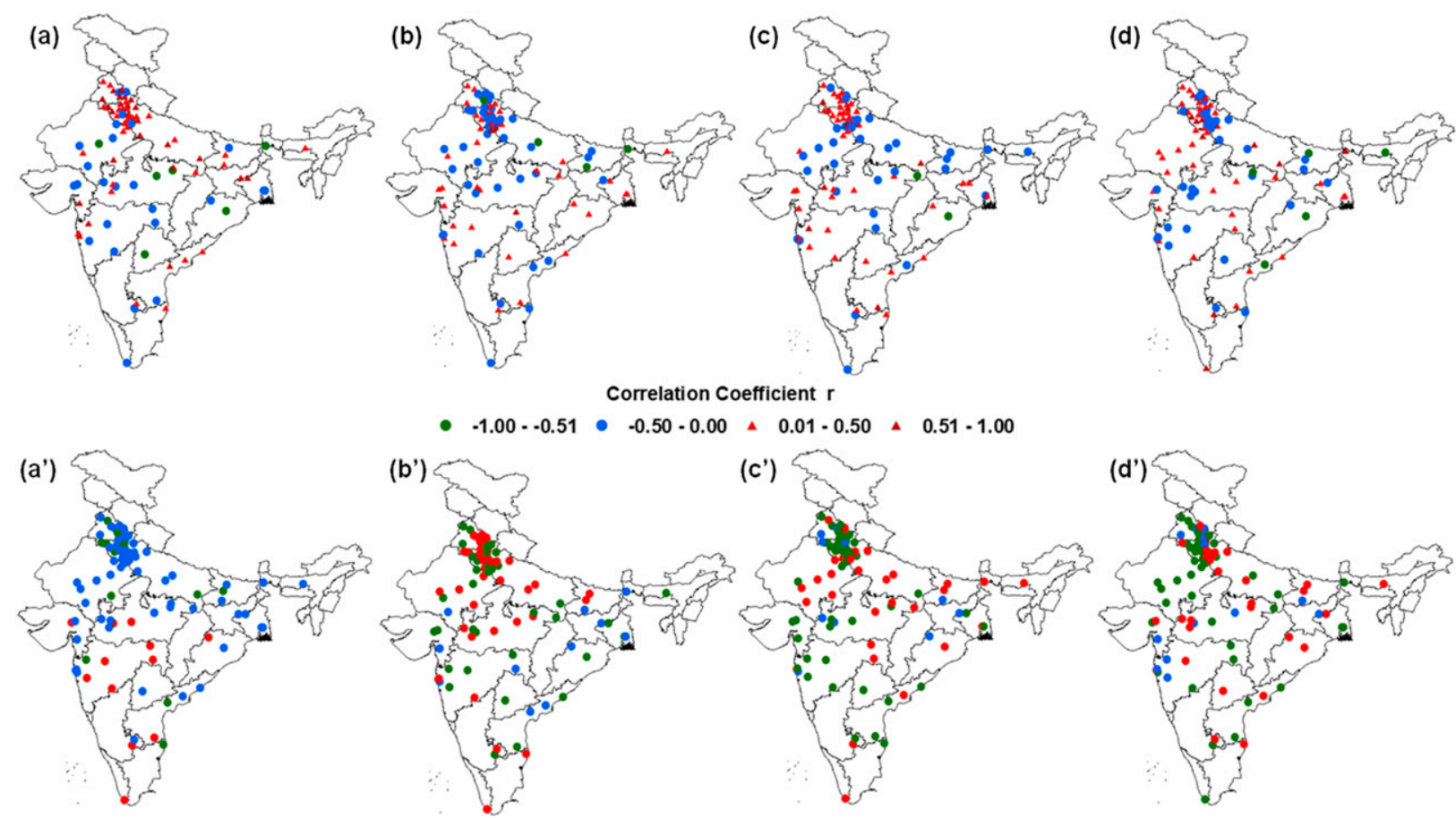

Statistical Probability

- Negative Significant $\bullet$ Positive Significant $\bullet$ Not Significant

FIG. 3. (a)-(d) Correlation between AQI values during the prelockdown and lockdown period of 2020 and the corresponding days in 2019 and $\left(a^{\prime}\right)-\left(d^{\prime}\right)$ the statistical significance $p$ of the computed correlation. for the $(a),\left(a^{\prime}\right)$ prelockdown and phases $(b),\left(b^{\prime}\right) 1 ;(c),\left(c^{\prime}\right) 2 ;$ and (d), (d') 3 of the lockdown. 


$$
\begin{aligned}
Q & =\sum_{j=1}^{n} \sum_{i=1}^{n}\left(\frac{A_{i j}}{h_{i}}\right)^{4}-\sum_{j=1}^{n}\left(\sum_{i=1}^{n} \frac{A_{i j}^{2}}{h_{i}^{2}}\right)^{2}, \\
h_{i}^{2} & =\sum_{j=1}^{n} A_{i j}^{2}, \quad \text { and } \\
Z_{i k} & =\sum_{i=1}^{n} A_{i j} R_{j k},
\end{aligned}
$$

where $n$ denotes the number of cities, $A_{i j}$ represents the loading of the $i$ th city on the $j$ th VR-principal component (PC), $h_{i}$ is the commonality of the $i$ th city, and $R_{j k}$ denotes the score of the $k$ th pollutant for the $j$ th rotated PC. The procedure of the VR technique aims to maximize the variances of the squared correlation $r$ between each rotated PC and the time series air pollutant data. To further identify the interactions between cities' backward trajectories and possible subregions, this study employed the VR technique on air pollutants data for all statistically significant cities derived from the MK test and TSE.

\section{Results and discussion}

The nationwide lockdown enforced restrictions, social distancing, and self-quarantine measures, which restricted transportation and industrial activity. During the stringent nationwide lockdown, skies across India were generally noted to be an unusual, azure blue (Picheta 2020). The countrywide pollution level dropped by $69 \%$. The country witnessed $32 \%$, $43 \%$, and $41 \%$ decreases in $\mathrm{PM}_{2.5}, \mathrm{SO}_{2}$, and $\mathrm{NO}_{2}$, respectively, during the lockdown period relative to prelockdown. On the other hand, the ground level $\mathrm{O}_{3}$ increased by $7 \%$ as compared with prelockdown. This increase in the $\mathrm{O}_{3}$ is likely due to increased insolation due to reduced aerosols and the reduction in the NOx levels, causing an ideal setup for in situ photochemical oxidant reactions (Aneja et al. 1994). Among the different pollutants, $\mathrm{PM}_{2.5}$ had a maximum reduction across most cities.

\section{a. Premonsoon meteorological conditions and urban air quality in India}

There are close linkages between urban air quality and the complex heating and dynamical processes associated with largescale circulation (Collier et al. 2018). In the western and southern regions, April is the warmest month; for northern regions, it is May. Temperatures average around $32^{\circ}-40^{\circ} \mathrm{C}$ across most of the country. The March-May average temperatures were higher than normal over most of the meteorological subdivisions of northwest, west, and central India and some subdivisions across south India (India Meteorological Department 2020). The atmospheric pressure is typically low across the country due to the warm surface conditions, and such a low pressure system often has high wind and ventilation potential, causing pollutants to be dispersed or washed by rain. As the intertropical convergence zone (ITCZ) begins to move toward the north, aerosol species are also transported long distances toward the tropical regions (Niyogi et al. 2007). Additionally, local urban meteorological processes in the Indian subcontinent can affect the AOD and level of air pollutants, which change the air quality during the premonsoon season.

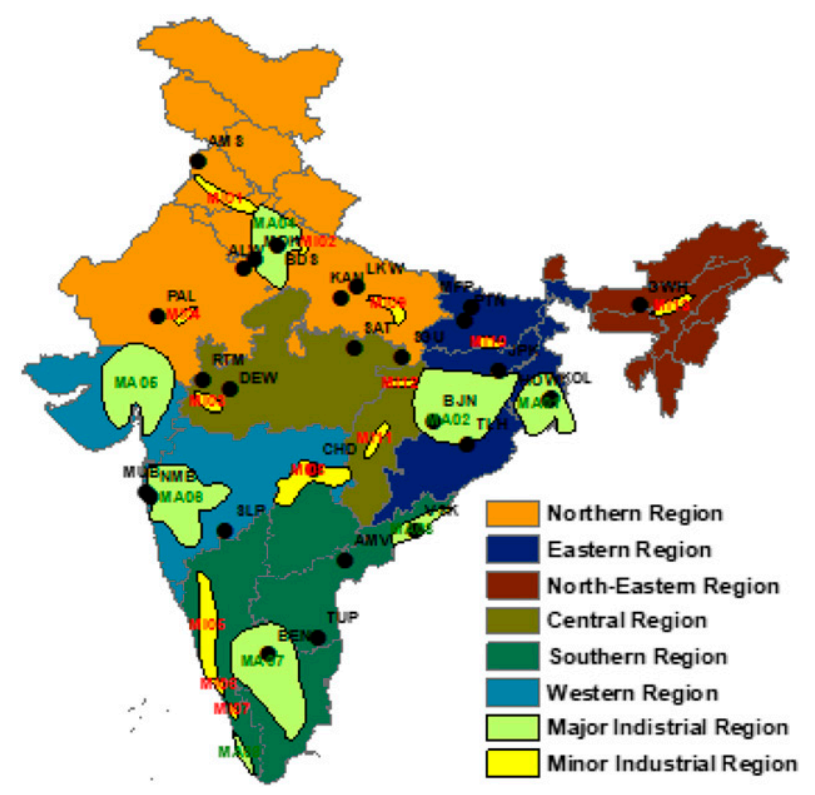

FIG. 4. Spatial distribution of 27 cities that exhibits statistically significant AQI trends $(\geq 1.96)$ during the different phases of the lockdown (black circles). Major (MA) and minor (MI) industrial regions are shown using light green and yellow polygons, respectively. The details are as follows: Hugli region (MA01), Chottanagpur industrial belt (MA02), Vishakhapatnam-Guntur belt (MA03), Gurgaon-Delhi-Meerut (MA04), Ahmedabad-Baroda region (MA05), Mumbai-Pune cluster (MA06), Bangalore-Tamil Nadu region (MA07), Kollam-Thiruvanathapuram belt (MA08), AmbalaAmritsar (MI01), Saharanpur-Muzaffarnagar (MI02), Indore-DewasUjjain (MI03), Jaipur-Ajmer (MI04), Kolhapur-South Kannada (MI05), Northern Malabar (MI06), Middle Malabar (MI07), AdilabadNizamabad (MI08), Allahabad-Varanasi-Mirsapur (MI09), BhojpurMunger (MI10), Durg-Raipur (MI11), Bilaspur-Korba (MI12), and Brahmaputra Valley (MI13).

\section{b. Response of urban AQI to 2020 lockdown}

Taylor diagrams for the prelockdown and lockdown period are used to examine how the overall variability of AQI for the 91 cities was affected by the COVID-19 restrictions (Fig. 2). Any given dataset is located in the Taylor diagram space at a radial distance from the origin, and azimuthal angle (measure counterclockwise from the $x$ axis) that are proportional to its standard deviation $\sigma_{o}$ and to its correlation $r$ with respect to a reference, respectively. Further, the standard deviation of the reference $\sigma_{r}$ is plotted on the $x$ axis. Distance between the data and reference locations on the diagram is proportional to its centered root-mean-square error (RMSE). The 2019 AQI data from the 91 cities for the same dates during which prelockdown (Fig. 2a) and lockdown (Fig. 2a) occurred in 2020 are used as reference points in the Taylor diagram (Fig. 2).

The $\sigma_{o}$ and $r$ for AQI are 30.2 and 0.65 during prelockdown, which decreases to 20.0 and 0.60 during the lockdown period, respectively. However, during the same period, the RMSE and $\sigma_{r}$ increased from 32 to 38 and from 35 to 49 . Thus, the Taylor diagrams (Fig. 2) show a notable contrast in the overall variability of AQI between the prelockdown and lockdown 
TABLE 1. The change and magnitude of AQI in the cities for different phases of lockdown.

\begin{tabular}{|c|c|c|c|c|c|c|}
\hline City & Code & Population $^{\mathrm{a}}$ & Criteria pollutants dropped & MK $(Z)$ value $^{\mathrm{b}}$ & Sen's slope & Remarks $^{c}$ \\
\hline Alwar & ALW & 341383 & $\mathrm{SO}_{2}$ & -2.46 & -1.246 & L1.0 \\
\hline Amaravati & AMV & 103400 & $\mathrm{SO}_{2}$ & -2.60 & -1.232 & L1.0 \\
\hline Amritsar & AMS & 1183705 & $\mathrm{CO}$ & -3.12 & -1.781 & $\mathrm{~L} 1.0$ \\
\hline Bengaluru & $\mathrm{BEN}$ & 8499399 & $\mathrm{SO}_{2}$ & -2.52 & -1.455 & L3.0 \\
\hline Brajrajnagar & $\mathrm{BJN}$ & 80403 & $\mathrm{PM}_{2.5}$ & -2.95 & -8.167 & $\mathrm{~L} 2.0$ \\
\hline Bulandshahr & BDS & 235310 & $\mathrm{SO}_{2}$ & -2.17 & -4.500 & $\mathrm{~L} 2.0$ \\
\hline Chandrapur & CHD & 321036 & $\mathrm{NH}_{3}$ & -2.53 & -1.143 & L2.0 \\
\hline Dewas & DEW & 289438 & $\mathrm{NO}_{2}$ & -3.36 & -4.588 & L2.0 \\
\hline Guwahati & GWH & 968549 & $\mathrm{NO}_{2}$ & -2.18 & -4.000 & $\mathrm{~L} 1.0$ \\
\hline Howrah & HOW & 1370448 & $\mathrm{NO}_{2}$ & -3.39 & -1.627 & L1.0 \\
\hline Jorapokhar & JPK & 96821 & $\mathrm{CO}$ & -1.97 & -1.000 & L2.0 \\
\hline Kanpur & KAN & 2920067 & $\mathrm{NO}_{2}$ & -3.89 & -4.167 & $\mathrm{~L} 2.0$ \\
\hline Kolkata & $\mathrm{KOL}$ & 14112536 & $\mathrm{NO}_{2}$ & -3.57 & -3.000 & L1.0 \\
\hline Lucknow & LKW & 2901474 & $\mathrm{NO}_{2}$ & -2.84 & -3.615 & L2.0 \\
\hline Mandikhera & MDK & 24750 & $\mathrm{CO}$ & -2.21 & -3.000 & L2.0 \\
\hline Mumbai & MUB & 18414288 & $\mathrm{PM}_{2.5}$ & -2.98 & -1.429 & L2.0 \\
\hline Muzaffarpur & MFP & 393724 & $\mathrm{NO}_{2}$ & -2.66 & -6.275 & L1.0 \\
\hline Navi Mumbai & NMB & 194999 & $\mathrm{NO}_{2}$ & -2.09 & -0.845 & $\mathrm{~L} 1.0$ \\
\hline Pali & PAL & 229956 & $\mathrm{NO}_{2}$ & -2.24 & -1.063 & $\mathrm{~L} 2.0$ \\
\hline Patna & PTN & 2046652 & $\mathrm{NO}_{2}$ & -3.82 & -3.412 & L2.0 \\
\hline Ratlam & RTM & 273892 & $\mathrm{SO}_{2}$ & -2.03 & -4.600 & L3.0 \\
\hline Satna & SAT & 283004 & $\mathrm{CO}$ & -2.24 & -1.533 & L2.0 \\
\hline Singrauli & SGU & 220295 & $\mathrm{NO}_{2}$ & -2.31 & -6.500 & $\mathrm{~L} 2.0$ \\
\hline Solapur & SLP & 951118 & $\mathrm{NH}_{3}$ & -2.31 & -2.167 & L3.0 \\
\hline Talcher & TLH & 40841 & $\mathrm{PM}_{10}$ & -2.36 & -4.295 & L3.0 \\
\hline Tirupati & TUP & 459985 & $\mathrm{NH}_{3}$ & -2.20 & -1.500 & L3.0 \\
\hline Visakhapatnam & VSK & 1730320 & $\mathrm{CO}$ & -2.31 & -1.833 & L3.0 \\
\hline
\end{tabular}

${ }^{\text {a }}$ Population figures denote only city population (Census of India 2011; https://censusindia.gov.in/2011-common/censusdata2011.html).

b 27 cities under statistically significant AQI changes at $\geq 1.96$ or $\leq 0.05$ level of 91 cities.

${ }^{\mathrm{c}}$ L1.0, L2.0, and L3.0 represent different lockdown phases.

periods. The dominant cause for the differing behavior is due to a substantial reduction in AQI standard deviation $\left(\Delta \sigma_{o} \sim\right.$ -10.2) during the lockdown, relative to reference observations $\left(\Delta \sigma_{r}=14\right)$. Note that these changes in $\sigma_{o}$ indicate an overall reduction in the amplitude of the time series of AQI due to COVID-19 restrictions. Reduction in AQI correlation $(\Delta r=$ -0.05 ) between prelockdown and lockdown periods is indicative of spatial and temporal differences in how the amplitude of AQI time series is affected during the lockdown.

\section{1) CORRELATION ANALYSIS}

As a part of the spatiotemporal analysis, we first examined the spatial variability of correlation for the 2019 and 2020 AQI time series separately for prelockdown and lockdown phases I-III (Fig. 3). During the prelockdown phase, the majority of the stations $(74 \%)$ show correlations that are not statistically significant (Fig. 3a). Of the $26 \%$ of the stations with statistically significant correlation, $13 \%$ show a negative correlation. These cities were primarily distributed in the western, southern, central, and eastern regions of India. Some of the cities with higher values of negative correlation include Pune (-0.45), Ahmedabad (-0.43), and Thiruvananthapuram ( -0.37$)$. Nonsignificant negative correlations are indicative of cities where voluntary slowdown of human activities were occurring prior to nationwide lockdown. During the lockdown, the proportion of cities with statistically significant correlation increased to $88 \%, 86 \%$, and $85 \%$, with $45 \%, 38 \%$, and $37 \%$ of the cities showing negative correlation (lowering of pollution) during lockdown phases I-III (Fig. 3). Higher (absolute) magnitudes of correlation coefficient were found over northern (e.g., Patiala with -0.6 during phase I), central (e.g., Singrauli with -0.67 during phase II), and northwest (e.g., Guwahati with -0.64 during phase III) regions of India.

Note that the differences between the lockdown stages could be potentially related to progressive relaxation of restrictions. During phase I, a limited number of retail activities were allowed to operate with a reduced workforce. During phases II and III, additional relaxations included the opening of agricultural businesses (dairy, aquaculture, and plantations) and farm supply businesses. Cargo transport via trucks, trains, and air transportation were also allowed to operate.

\section{2) AQI CHANGE ANALYSIS}

We computed the significance and magnitude of the AQI trends for all cities using the nonparametric (distribution free) MK trend test and TSE, respectively. Using this analysis, we identified 27 cities with AQI showing a statistically decreasing trend (improved air quality) during at least one of the lockdown phases. Of these, 8,13 , and 6 cities exhibit a decreasing trend during phases I, II, and III of the lockdown. We found a 

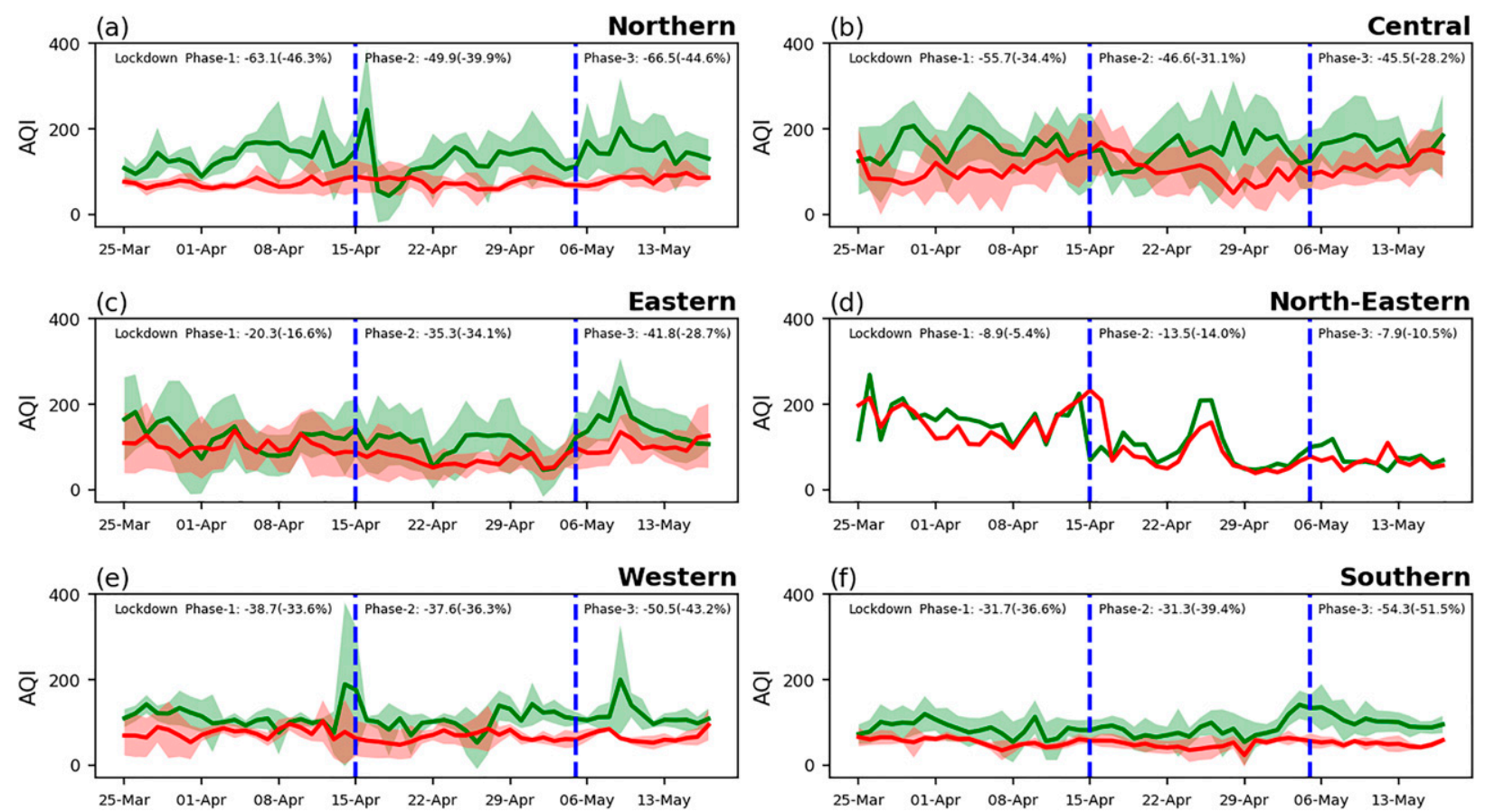

FIG. 5. Time series of AQI for the 27 stations with statistically significant decreasing trends averaged as a function of geographical region. The green and red solid lines are mean AQI time series for 2019 and 2020, respectively. Green and red shading show the bounds defined by mean plus/minus 1 standard deviation. Vertical dashed lines in the panels indicate the date ranges for the three phases of the lockdown. The mean difference in AQI values between 2019 and 2020 and the corresponding percentage change (in parentheses) during each phase of the lockdown are also shown.

majority of the stations with a statistically significant decreasing trend to be located close to industrial locations (Fig. 4). The highest magnitudes of negative trends indicate by TSE are found over central and eastern regions, with the maximum value occurring at Brajrajnagar (-8.17) (Table 1). We also examined which of the criteria pollutant showed maximum percentage decrease in concentration relative to the prelockdown period. We found $\mathrm{NO}_{2}$ to experience the maximum percentage drop in association with the negative AQI trends (Table 1). One of the features of these results is that while the general perception has been that air quality improved during the lockdown, the statistical measures indicate there is considerable spatiotemporal variability in the results.

We grouped the 27 cities according to regions within which they are located and computed the regional average time series of AQI and criteria pollutant concentrations for 2019 and 2020. These time series show that the mean AQI for 2020 remained consistently smaller than that for 2019 (Fig. 5). Standard derivation of AQI also diminished during 2020. The paired $t$ test shows that there are statistically significant differences in AQI between 2019 and 2020 for all regions and during all phases. Maximum percentage reduction in AQI exceeding 54\% occurs in the southern region during the third phase of the lockdown (Fig. 5f) while the northern region experiences the highest percentage reduction in AQI during the first two phases of the lockdown (Fig. 5a). All regions, with the exception of eastern and northeastern regions show AQI reductions exceeding $30 \%$ during all phases of the lockdown. The northeastern region experiences the least reduction in AQI, exceeding $10 \%$ only during phase III. The eastern region also shows anomalous behavior relative to other regions, experiencing only $16.6 \%$ reduction in AQI during phase I of the lockdown (Fig. 5c).

Region-averaged time series of $\mathrm{PM}_{2.5}$ show some patterns similar to that for AQI (Fig. 6). The maximum percentage reduction of $\mathrm{PM}_{2.5}$ exceeding $65 \%$ occurs over the southern region during phase III (Fig. 6f) while the northern region shows the highest percentage reduction during phase II and III (Fig. 6a). Least percentage reductions in $\mathrm{PM}_{2.5}$ are found over the eastern and western regions. Percentage reductions in $\mathrm{NO}_{2}$ during all three phases are highest in the southern region (Fig. 7f). Least reduction in $\mathrm{NO}_{2}$ is found over the northeastern region during the third phase (Fig. 7d). Northern and eastern regions also show differing behavior, with the percentage reduction of $\mathrm{NO}_{2}$ being less than one-half of that experienced by other regions during phases II and III. Regionally averaged $\mathrm{O}_{3}$ also show statistically significant reductions ranging from $0.4 \%$ to $33 \%$ in all regions with the exception of the eastern region (Fig. 8). Concentrations of $\mathrm{O}_{3}$ for the eastern region increase during all phases and exceeding $49 \%$ during both phases II and III (Fig. 8c). This increase is likely due to increased insolation due to reduced aerosols and reduced NOx levels, resulting in an ideal setup for in situ photochemical oxidant reactions (Aneja et al. 1994). Of the other pollutants, $\mathrm{NH}_{3}, \mathrm{CO}$, and $\mathrm{SO}_{2}$ show maximum percentage reduction in the northern, central, 

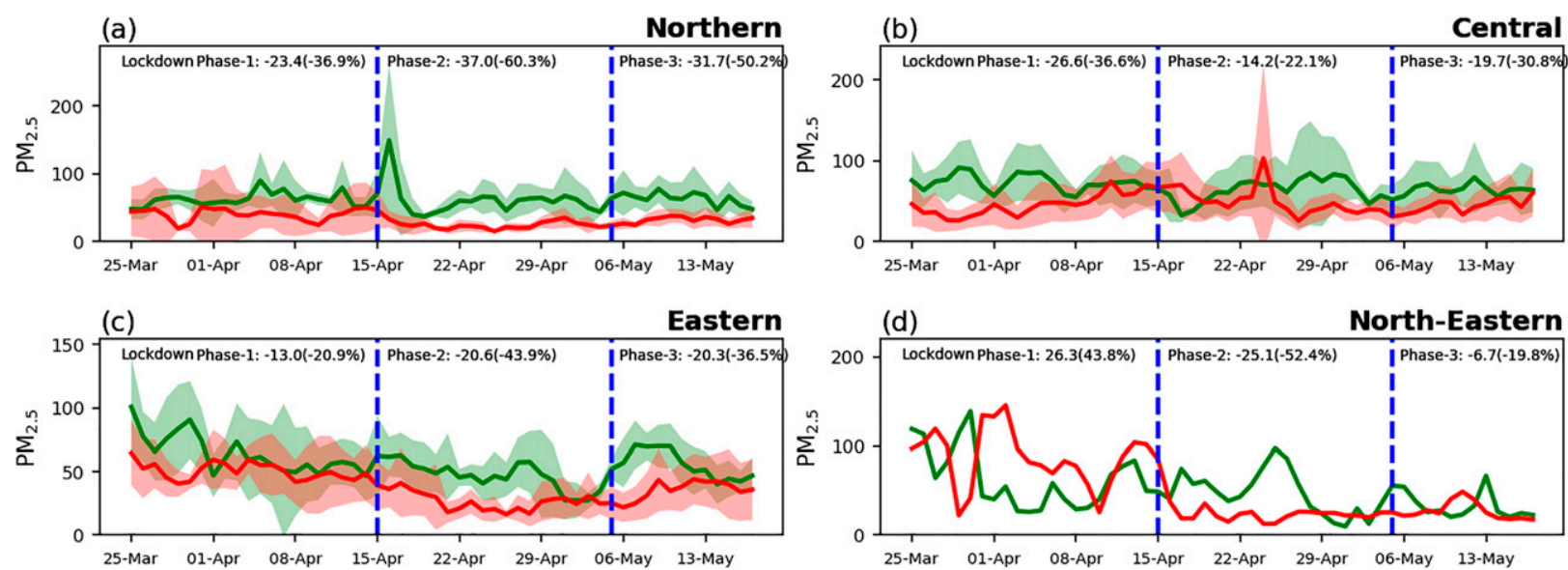

(d)

North-Eastern

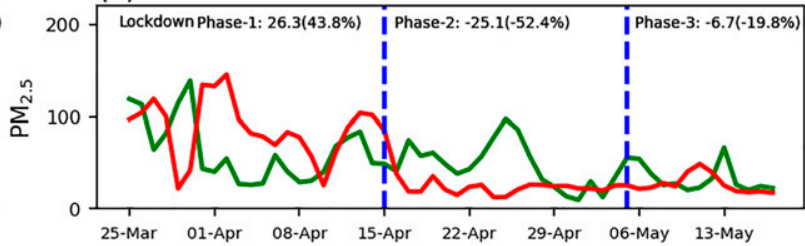

(e)

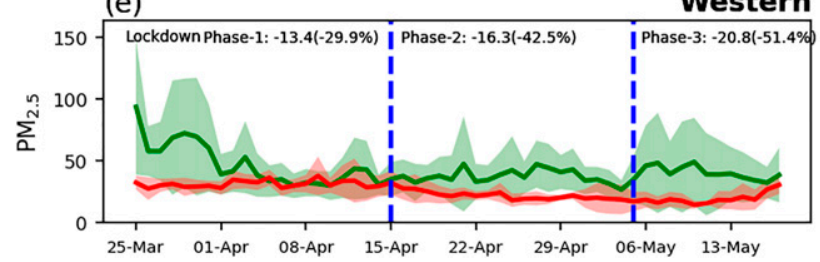

(f)

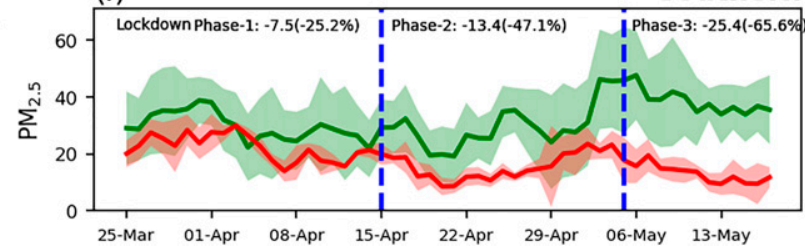

FIG. 6. As in Fig. 5, but for $\mathrm{PM}_{2.5}$.

and western regions during all phases of the lockdown (Table 2). Minimum percentage reductions of these variables occur either over eastern or northeastern regions. The $\mathrm{PM}_{10}$ pollutant show behavior very similar to $\mathrm{PM}_{2.5}$ for most regions.

We also examined nationwide average changes in AQI and pollutants between 2020 and 2019 for the 27 stations that showed statistically significant trends. This analysis showed average decrease in $\mathrm{AQI}, \mathrm{PM}_{2.5}, \mathrm{PM}_{10}, \mathrm{NO}_{2}, \mathrm{O}_{3}, \mathrm{SO}_{2}, \mathrm{NH}_{3}$, and $\mathrm{CO}$ of $33 \%$, $36 \%, 40 \%, 58 \%, 5 \%, 25 \%, 28 \%$, and $60 \%$. We also compared the differences between the prelockdown and lockdown periods of 2020 and found a mean reduction in AQI, $\mathrm{PM}_{2.5}, \mathrm{PM}_{10}, \mathrm{NO}_{2}, \mathrm{SO}_{2}$, $\mathrm{NH}_{3}$, and $\mathrm{CO}$ of $69 \%, 32 \%, 27 \%, 41 \%, 43 \%, 12 \%$, and $17 \%$. On the other hand, there was a mean $7 \%$ increase in $\mathrm{O}_{3}$ during the lockdown when relative to the prelockdown period. However, this is also likely due to the seasonal increase in $\mathrm{O}_{3}$ concentration, not only related to the lockdown period. This was verified by examining the differences in $\mathrm{O}_{3}$ concentration between the prelockdown and lockdown days of the year for 2019. We found a similar seasonal increase for that year also, with the magnitude of increase being higher for 2019. Thus, the nationwide average effect of lockdown on $\mathrm{O}_{3}$ concentrations is to cause a reduction.

When all the 91 stations are considered, the maximum number of cities (43 of 91) experiencing statistically significant reductions in AQI occurred during the second phase of the lockdown, with lesser numbers being affected during the first (27) and third (20) phases.

\section{c. Major pollutants in the cities under changing AQI during COVID lockdown}

Bartlett's test of sphericity revealed that the air pollutants were correlated and nonorthogonal. This suggests that PCA can be effectively used for understanding the variability in the air pollutant data (McNeil et al. 2005; Azid et al. 2014). The Kaiser-Meyer-Olkin test was performed to find the sampling adequacy for the different phases (Dziuban and Shirkey 1974). These two statistical tests confirmed that the data used are "adequate" and can be used for subsequent analysis. The variance factor (VF) technique was used in this analysis to clarify the relationship among factors (Bartuccelli et al. 2006).

After VR, from seven PCs, only two VFs were selected with an eigenvalue greater than 1.00 for prelockdown, lockdown phase I, lockdown phase II, and lockdown phase III, as $53.33 \%$, $54.52 \%, 61.77 \%$, and $62.48 \%$ of the variance of the air pollutants, respectively. Despite the cumulative variance being less than $70 \%$, the factors' cutoff point was determined using a screen plot for each case. The eigenvalue less than $100(<1.00)$ are neglected because of confounding with more important factors. That is, multicollinearity was present among air pollutants.

The VFs with values greater than 0.500 were set as the selection threshold, which exhibits moderate to strong loadings on the VR factors. Table 3 summarizes the constituents satisfying the 0.5 factor-loading threshold. These variables are $\mathrm{PM}_{2.5}, \mathrm{PM}_{10}, \mathrm{NH}_{3}, \mathrm{NO}_{2}$, and $\mathrm{O}_{3}$ for prelockdown. For lockdown phase I, $\mathrm{PM}_{2.5}, \mathrm{PM}_{10}, \mathrm{SO}_{2}, \mathrm{NO}_{2}$, and $\mathrm{NH}_{3}$ are the main air pollutants. For lockdown phases II and III, additionally, $\mathrm{O}_{3}$ is also identified as a major source. These pollutants are then classified as the major contributing pollutants at the statistically significant cities (decreasing AQI) in India.

The VF1 contributes about $31.44 \%$ of the air pollutant data variation in the case of the prelockdown period. It has high loadings from three variables: $\mathrm{PM}_{2.5}(0.844), \mathrm{PM}_{10}(0.891)$, and $\mathrm{NH}_{3}$ (0.746). This factor can be interpreted as a measure of 

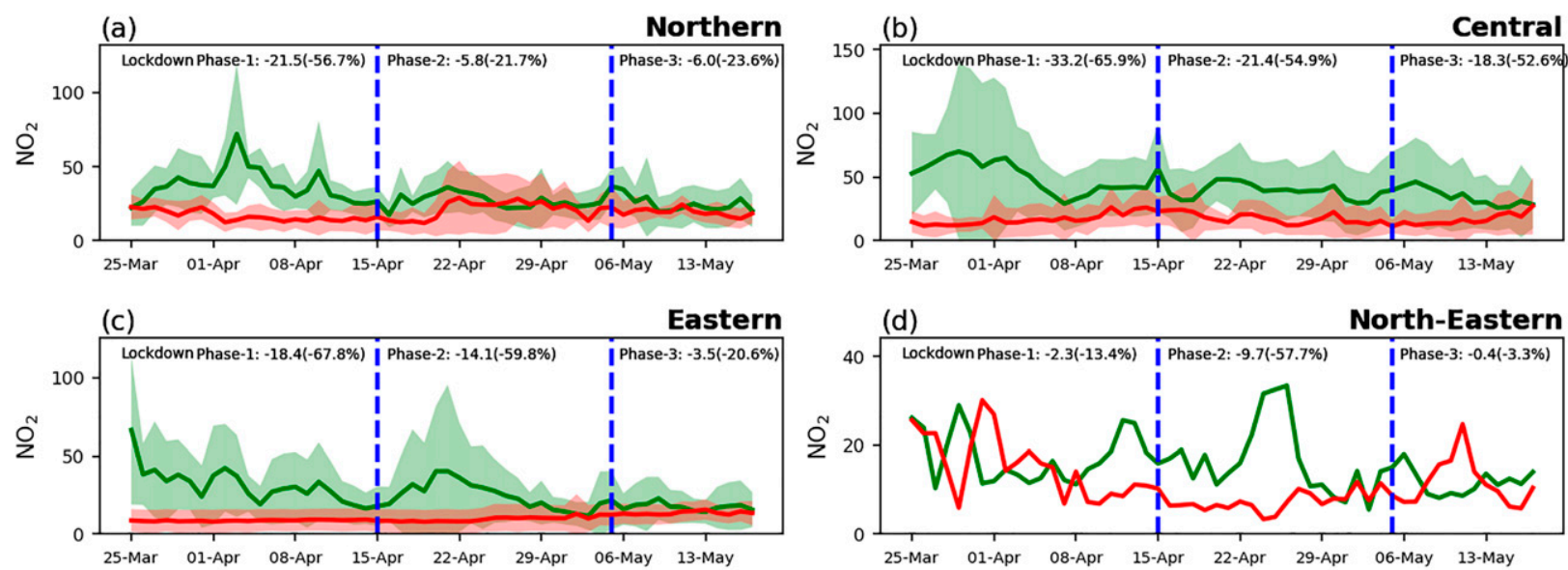

(d)

North-Eastern
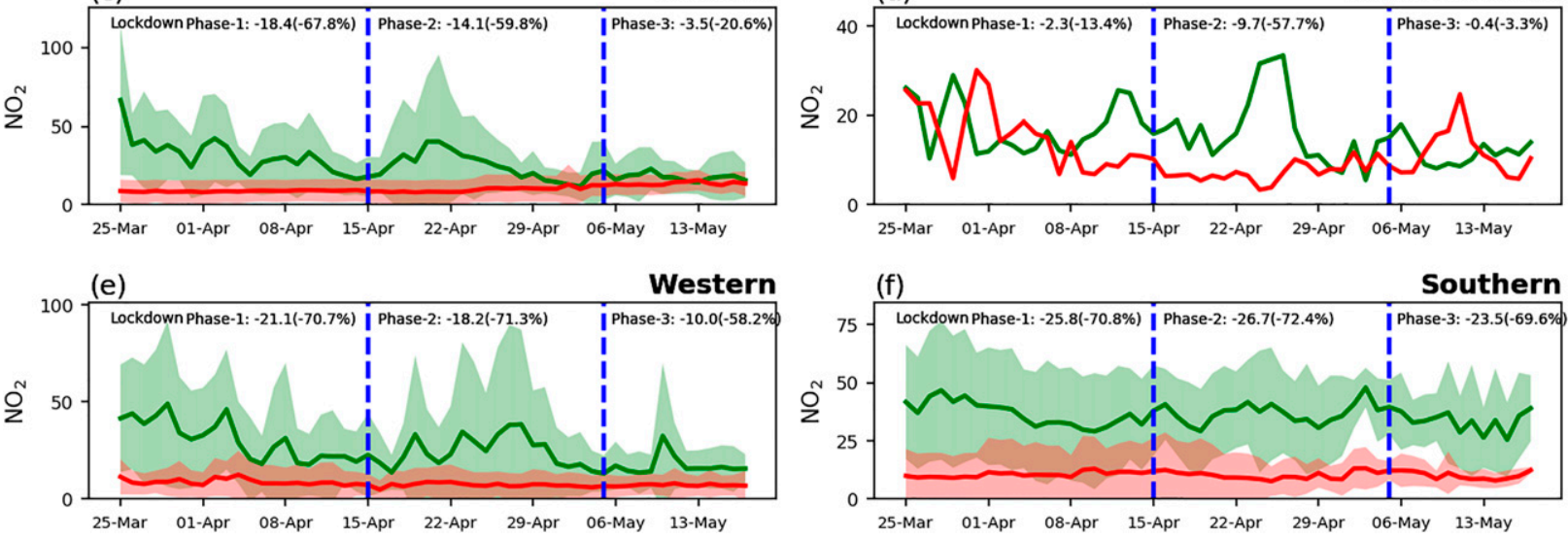

FIG. 7. As in Fig. 5, but for $\mathrm{NO}_{2}$.

primary and secondary pollutants. As a secondary particulate precursor, $\mathrm{NH}_{3}$ also contributes to the formation of particulate aerosols in the atmosphere. The VF1 highlights that about $30.19 \%$ of the variation in the air pollutant data is in the case of lockdown phase $\mathrm{I}$, and the contributions are from $\mathrm{PM}_{2.5}$ (0.881), $\mathrm{PM}_{10}(0.830)$, and $\mathrm{SO}_{2}(0.757)$. The variation in the air pollutants in the case of lockdown phase II for VF1 also contributes about $34.09 \%$. This phase shows the significance of (a)

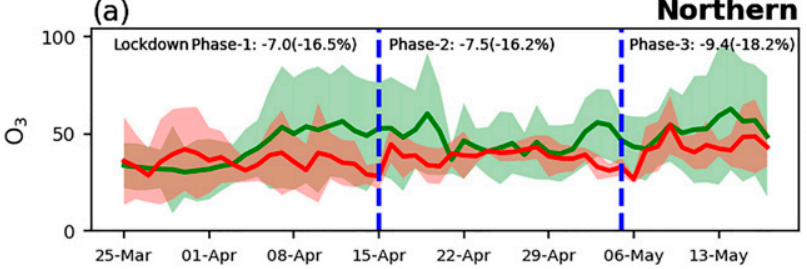

(c)

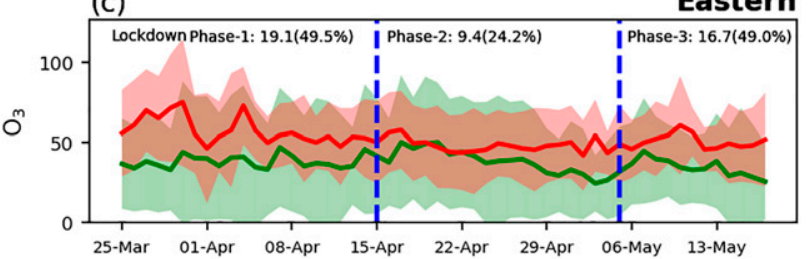

(e)

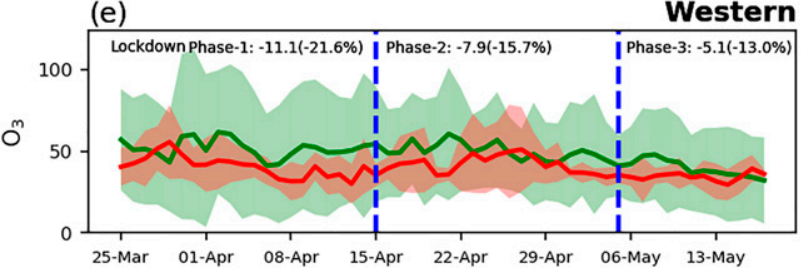

(b)

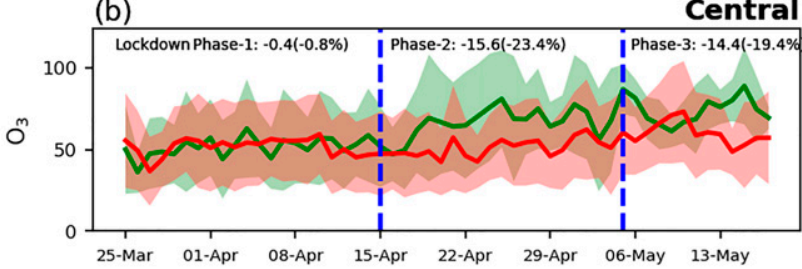

(d)

North-Eastern

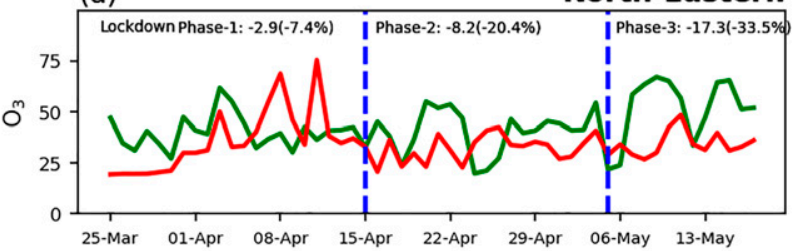

Southern

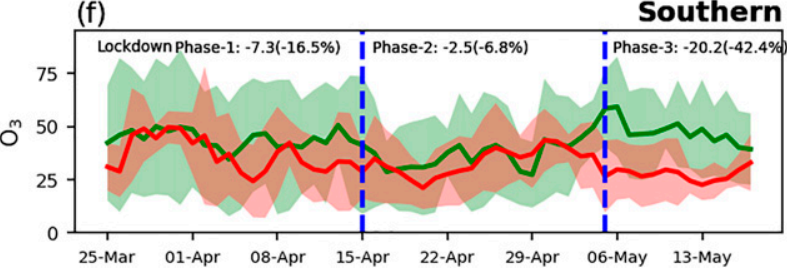

FIG. 8. As in Fig. 5, but for $\mathrm{O}_{3}$. 
TABLE 2. The mean difference in concentrations of $\mathrm{PM}_{10}, \mathrm{SO}_{2}, \mathrm{NH}_{3}$, and $\mathrm{CO}$ between 2020 and 2019 for the three phase of lockdown as a function of geographic region. The differences are computed for the 27 stations that showed statistically significant decreasing trends. The percentage change is shown in parentheses. Air quality stations within each region are shown in the second column. Units of all criteria pollutants are in micrograms per meter cubed except $\mathrm{CO}$, which is in milligrams per meter cubed.

\begin{tabular}{|c|c|c|c|c|c|c|}
\hline \multirow[b]{2}{*}{ Region } & \multirow[b]{2}{*}{ Air quality stations } & \multirow{2}{*}{$\begin{array}{l}\text { Lockdown } \\
\text { phases }\end{array}$} & \multicolumn{4}{|c|}{ Pollutant drop (\%) respect to 2019} \\
\hline & & & $\mathrm{PM}_{10}$ & $\mathrm{SO}_{2}$ & $\mathrm{NH}_{3}$ & $\mathrm{CO}$ \\
\hline \multirow[t]{3}{*}{ Northern } & Alwar, Amritsar, Mandikhera, Pali & L1.0 & $\begin{array}{l}-53.3 \\
(-37.7 \%)\end{array}$ & $-1(-6.5 \%)$ & $-13.9(51.8 \%)$ & $0.5(68.3 \%)$ \\
\hline & & $\mathrm{L} 2.0$ & $\begin{array}{l}-92.5 \\
(-61.7 \%)\end{array}$ & $-3.9(23 \%)$ & $-5.7(30.5 \%)$ & $\begin{array}{l}-0.2 \\
(-31.1 \%)\end{array}$ \\
\hline & & L3.0 & $-84.7(56 \%)$ & $0.3(2.4 \%)$ & $\begin{array}{l}-17.9 \\
(-61.1 \%)\end{array}$ & $\begin{array}{l}-0.3 \\
(-35.3 \%)\end{array}$ \\
\hline \multirow[t]{3}{*}{ Central } & $\begin{array}{l}\text { Bulandshahr, Dewas, Kanpur, } \\
\text { Lucknow, Ratlam, Satna, Singrauli }\end{array}$ & L1.0 & $\begin{array}{l}-54.2 \\
(-31.7 \%)\end{array}$ & $-8.7(33.6 \%)$ & $-5.6(24.3 \%)$ & $\begin{array}{l}-3.1 \\
(-80.1 \%)\end{array}$ \\
\hline & & $\mathrm{L} 2.0$ & $\begin{array}{l}-45.9 \\
(-28.9 \%)\end{array}$ & $-5.4(22.8 \%)$ & $-1.9(-9.3 \%)$ & $\begin{array}{l}-4.3 \\
(-85.4 \%)\end{array}$ \\
\hline & & L3.0 & $-67.5(37.5 \%)$ & $\begin{array}{l}-11.1 \\
(42.4 \%)\end{array}$ & $\begin{array}{l}-4.4 \\
(-23.4 \%)\end{array}$ & $\begin{array}{l}-2.8 \\
(-83.1 \%)\end{array}$ \\
\hline \multirow[t]{3}{*}{ Eastern } & $\begin{array}{l}\text { Brajrajnagar, Howrah, Jorapokhar, } \\
\text { Kolkata, Muzaffarpur, patna, }\end{array}$ & $\mathrm{L} 1.0$ & $-47.8(-35 \%)$ & $-2.4(13.7 \%)$ & $-0.7(-3.5 \%)$ & $\begin{array}{l}-0.1 \\
(-7.4 \%)\end{array}$ \\
\hline & Talcher & $\mathrm{L} 2.0$ & $\begin{array}{l}-57.7 \\
(-48.3 \%)\end{array}$ & $-4.6(26.3 \%)$ & $\begin{array}{l}-4.5 \\
(-24.7 \%)\end{array}$ & $0.1(11.7 \%)$ \\
\hline & & L3.0 & $-57.2(41 \%)$ & $-1(-6.8 \%)$ & $-1.3(-8.2 \%)$ & $\begin{array}{l}-0.2 \\
(-24.3 \%)\end{array}$ \\
\hline \multirow[t]{3}{*}{ Northeastern } & Guwahati & L1.0 & $\begin{array}{l}-64.2 \\
(-61.5 \%)\end{array}$ & $-4.7(21.8 \%)$ & $-0.6(-3.7 \%)$ & $\begin{array}{l}-0.2 \\
(-21.4 \%)\end{array}$ \\
\hline & & $\mathrm{L} 2.0$ & $-41(52.9 \%)$ & $-4.6(23.5 \%)$ & $-0.2(-1.5 \%)$ & $\begin{array}{l}-0.3 \\
(-38.9 \%)\end{array}$ \\
\hline & & L3.0 & $-10.5(18.7)$ & $-6(29 \%)$ & $\begin{array}{l}-6.9 \\
(-53.8 \%)\end{array}$ & $\begin{array}{c}-0.1 \\
(-18.4 \%)\end{array}$ \\
\hline \multirow[t]{3}{*}{ Western } & $\begin{array}{l}\text { Chandraour, Mumbai, Navi Mumbai, } \\
\text { Solapur }\end{array}$ & L1.0 & $\begin{array}{l}-51.5 \\
(-42.3 \%)\end{array}$ & $\begin{array}{c}-13 \\
(-56.3 \%)\end{array}$ & $-6.9(33.7 \%)$ & $\begin{array}{l}-0.9 \\
(-55.1 \%)\end{array}$ \\
\hline & & $\mathrm{L} 2.0$ & $\begin{array}{l}-55.8 \\
(-51.1 \%)\end{array}$ & $-9.6(45 \%)$ & $\begin{array}{l}-2.7 \\
(-15.1 \%)\end{array}$ & $\begin{array}{l}-0.9 \\
(-60.6 \%)\end{array}$ \\
\hline & & L3.0 & $52.6(-48.8 \%)$ & $-7.2(33.2 \%)$ & $\begin{array}{l}-8.4 \\
(-41.5 \%)\end{array}$ & $\begin{array}{l}-0.9 \\
(-60.6 \%)\end{array}$ \\
\hline \multirow[t]{3}{*}{ Southern } & $\begin{array}{l}\text { Amaravati, Bengaluru, Tirupati, } \\
\text { Visakhapatnam }\end{array}$ & L1.0 & $-36(-44.6 \%)$ & $1.7(17.6 \%)$ & $-3.2(24.3 \%)$ & $\begin{array}{l}-0.2 \\
(-33.8 \%)\end{array}$ \\
\hline & & $\mathrm{L} 2.0$ & $-41.1(52.3 \%)$ & $0.7(8.2 \%)$ & $\begin{array}{l}-11.2 \\
(-60.6 \%)\end{array}$ & $\begin{array}{l}-0.3 \\
(-41.6 \%)\end{array}$ \\
\hline & & L3.0 & $-70.9(63.3 \%)$ & $0.0(0.2 \%)$ & $\begin{array}{l}-8.8 \\
(-53.2 \%)\end{array}$ & $-0.3(-42 \%)$ \\
\hline
\end{tabular}

$\mathrm{PM}_{2.5}(0.777), \mathrm{PM}_{10}(0.683), \mathrm{SO}_{2}(0.667)$, and $\mathrm{O}_{3}(0.777)$ on the air quality changes. For lockdown phase III, VF1 yields $36.45 \%$ of the variation for the same four pollutants: $\mathrm{PM}_{2.5}(0.765)$, $\mathrm{PM}_{10}$ (0.692), $\mathrm{SO}_{2}$ (0.750), and $\mathrm{O}_{3}(0.792)$.

The VF 2 confirms $22.09 \%$ of the variance for the prelockdown period. It highlights the loading in $\mathrm{NO}_{2}(0.541)$ and $\mathrm{O}_{3}(0.874)$. In lockdown phase I, VF2 exhibits $24.33 \%$ of the variance. It shows signs of high loading in $\mathrm{NO}_{2}(0.899)$ and $\mathrm{NH}_{3}(0.827)$. Conversely, $27.68 \%$ of the variance is associated with VF2 for lockdown phase II, with loading from $\mathrm{PM}_{10}(0.566), \mathrm{NO}_{2}(0.798)$, and $\mathrm{NH}_{3}(0.851)$. The VF2 also yields $26.02 \%$ of the variance for lockdown phase III, with loading in $\mathrm{PM}_{10}(0.500), \mathrm{NO}_{2}(0.745)$, and $\mathrm{NH}_{3}(0.864)$. The contribution of criteria pollutants after varimax rotation is summarized in Table 4.
The loadings and factor scores pertaining to the air pollutant patterns are found by grouping into subcriteria pollutants. Factor scores are composites of the air pollutants that are used to make the latent factor into an observed air pollutant level to give it a scale. Each factor is a linear combination of all air pollutants with each eigenvector (weighed for each variable). The factor is positive when the air pollutants with greater weight take high values and negative otherwise. Table 5 displays the factor scores for the 27 cities following VR. These scores are standardized, with a zero mean, and about twothirds of the values lie between \pm 1.00 . Scores beyond \pm 1.00 , therefore, are unusually high or low.

The concentration of these criteria pollutants is related to the primary pollutant $\left(\mathrm{SO}_{2}\right.$ and $\left.\mathrm{NH}_{3}\right)$, secondary pollutant 
TABLE 3. Variance factors after varimax rotation, and the possible source pollutants in the cities. VFs with absolute values greater than 0.500 (boldface type) were set as the selection threshold.

\begin{tabular}{|c|c|c|c|c|c|c|c|c|}
\hline \multirow[b]{2}{*}{ Pollutants } & \multicolumn{2}{|c|}{ Before lockdown } & \multicolumn{2}{|c|}{ Lockdown phase I } & \multicolumn{2}{|c|}{ Lockdown phase II } & \multicolumn{2}{|c|}{ Lockdown phase III } \\
\hline & VFI & VF2 & VFI & VF2 & VFI & VF2 & VFI & VF2 \\
\hline $\mathrm{PM}_{2.5}$ & 0.844 & 0.137 & 0.881 & 0.236 & 0.777 & 0.441 & 0.765 & 0.405 \\
\hline $\mathrm{PM}_{10}$ & 0.891 & -0.003 & 0.830 & 0.267 & 0.683 & 0.566 & 0.692 & 0.500 \\
\hline $\mathrm{NO}_{2}$ & 0.261 & 0.541 & 0.154 & 0.899 & 0.185 & 0.798 & 0.261 & 0.745 \\
\hline $\mathrm{NH}_{3}$ & 0.746 & -0.165 & 0.143 & 0.827 & 0.070 & 0.851 & 0.061 & 0.864 \\
\hline $\mathrm{SO}_{2}$ & 0.238 & 0.462 & 0.757 & -0.148 & 0.676 & 0.077 & 0.750 & -0.183 \\
\hline $\mathrm{CO}$ & 0.070 & 0.480 & -0.023 & 0.007 & 0.466 & -0.235 & 0.476 & 0.205 \\
\hline $\mathrm{O}_{3}$ & -0.094 & 0.874 & 0.176 & 0.247 & 0.777 & -0.034 & 0.792 & 0.178 \\
\hline Eigenvalue & 2.25 & 1.49 & 2.56 & 1.26 & 3.04 & 1.28 & 3.26 & 1.12 \\
\hline Variability (\%) & 31.44 & 22.09 & 30.19 & 24.33 & 34.09 & 27.68 & 36.45 & 26.02 \\
\hline Cumulative (\%) & 31.44 & 53.53 & 30.19 & 54.52 & 34.09 & 61.77 & 36.45 & 62.48 \\
\hline
\end{tabular}

$\left(\mathrm{NO}_{2}\right.$ and $\left.\mathrm{O}_{3}\right)$, and nongaseous primary and secondary pollutants $\left(\mathrm{PM}_{2.5}\right.$ and $\left.\mathrm{PM}_{10}\right)$.

\section{Case study: Kolkata-Howrah region}

The Kolkata-Howrah region lies near the banks of River Hooghly in eastern India. This region is one of the largest trade and commerce center in India and is located about $150 \mathrm{~km}$ north of the Bay of Bengal (BoB), over the Gangetic delta plains. To accommodate the increasing population and its expanding demands for housing, transport, material goods, and a range of services, the pressure on land and environmental resources has continued to increase since the early days of its urban history. The increase in vehicular traffic, industrial emission, and intensive use of land conversion for urban development have multiplier effects on the region's air quality. The region's annual travel demand has increased at a rate of $5.2 \%$ to vehicular traffic between the 1990s and 2019 .

For this region, data from 10 West Bengal Pollution Control Board air quality monitoring stations is analyzed. A number of metropolitan cities in India showed significant improvement in the ambient air quality during the COVID-19 pandemic. Typically, the regions with historically higher levels of $\mathrm{PM}_{2.5}$, $\mathrm{PM}_{10}, \mathrm{NO}_{2}$, and $\mathrm{O}_{3}$ pollutants yielded the most significant drops in pollution. Consistent with the broader finding, the Kolkata-Howrah region showed considerably improved air quality during the pandemic due to lockdown as well as rainfall spells.
For the corresponding period in 2019, the AQI varied between 100 and 300 for different air monitoring stations in the region like Baranagar, Kolkata, and Ghusuri, Howrah (West Bengal Pollution Control Board 2020). Even before the lockdown period, the AQI hovered between 100 and 260 across different air monitoring stations.

The effect of winds on $\mathrm{NO}_{2}$ concentrations in the KolkataHowrah region was examined using a pollution rose diagram. Figure 9 shows the concentration for 25 March to 17 May 2020 for the air quality monitoring stations in the Kolkata-Howrah region. Except for Fort William, Rabindra Sarobar, and Victoria, the wind pattern in most stations were in the south and southwest wind direction. The minimum and maximum speeds were between 0.20 and $2.90 \mathrm{~m} \mathrm{~s}^{-1}$ for Rabindra Sarobar (interior green space location) and Ghusuri (riverside industrial). The average speed is $0.92 \mathrm{~m} \mathrm{~s}^{-1}$ across the different stations. Most of the $\mathrm{NO}_{2}$ was sourced (transportation and industries) from the south and southwestern parts of the region. The greater the distance from the pollution source, the larger effect of wind direction and wind speed on horizontal dilution and mixing layer height is expected, which controls dispersion in the lower atmosphere.

\section{a. Station-based changes in criteria pollutants}

Figure 10 shows the station-based changes in the daily concentrations of pollutants for 10 stations of the KolkataHowrah region for the periods of lockdown phase I, lockdown phase II, and lockdown phase III. Overall, around 49\%, 45\%,

TABLE 4. Contribution (\%) of the pollutants after varimax rotation. The boldface type corresponds to the selection thresholds in Table 3.

\begin{tabular}{|c|c|c|c|c|c|c|c|c|}
\hline \multirow[b]{2}{*}{ Pollutants } & \multicolumn{2}{|c|}{ Before lockdown } & \multicolumn{2}{|c|}{ Lockdown phase I } & \multicolumn{2}{|c|}{ Lockdown phase II } & \multicolumn{2}{|c|}{ Lockdown phase III } \\
\hline & VFI & VF2 & VFI & VF2 & VFI & $\mathrm{VF} 2$ & VFI & $\mathrm{VF} 2$ \\
\hline $\mathrm{PM}_{2.5}$ & 32.39 & 1.21 & 36.75 & 3.26 & 25.28 & 10.03 & 22.93 & 8.99 \\
\hline $\mathrm{PM}_{10}$ & 36.05 & 0.00 & 32.57 & 4.18 & 19.52 & 16.53 & 18.76 & 13.74 \\
\hline $\mathrm{NO}_{2}$ & 3.09 & 18.93 & 1.12 & 47.50 & 1.43 & 32.90 & 2.66 & 30.44 \\
\hline $\mathrm{NH}_{3}$ & 25.28 & 1.76 & 0.96 & 40.20 & 0.20 & 37.34 & 0.15 & 40.96 \\
\hline $\mathrm{SO}_{2}$ & 2.57 & 13.83 & 27.10 & 1.29 & 19.16 & 0.31 & 22.06 & 1.84 \\
\hline $\mathrm{CO}$ & 0.22 & 14.90 & 0.02 & 0.00 & 9.09 & 2.85 & 8.88 & 2.30 \\
\hline $\mathrm{O}_{3}$ & 0.40 & 49.36 & 1.47 & 3.58 & 25.32 & 0.06 & 24.55 & 1.73 \\
\hline
\end{tabular}


TABLE 5. Derived standardized factor scores after varimax rotation.

\begin{tabular}{|c|c|c|c|c|c|c|c|c|c|}
\hline \multirow[b]{2}{*}{ City } & \multirow[b]{2}{*}{ Code } & \multicolumn{2}{|c|}{ Before lockdown } & \multicolumn{2}{|c|}{ Lockdown phase I } & \multicolumn{2}{|c|}{ Lockdown phase II } & \multicolumn{2}{|c|}{ Lockdown phase III } \\
\hline & & VFI & VF2 & VFI & VF2 & VFI & VF2 & VFI & VF2 \\
\hline Alwar & ALW & 0.434 & -0.448 & -0.889 & 0.920 & -0.561 & 0.479 & -0.384 & 0.445 \\
\hline Amaravati & AMV & -1.496 & -0.794 & -1.007 & -0.211 & -1.118 & -0.216 & -1.156 & -0.805 \\
\hline Amritsar & AMS & -0.642 & -0.696 & -0.947 & -0.467 & -0.349 & -0.097 & -0.024 & -0.007 \\
\hline Bengaluru & $\mathrm{BEN}$ & -1.020 & 0.592 & -0.504 & -0.841 & -0.487 & -0.806 & -0.455 & -0.197 \\
\hline Brajrajnagar & BJN & 0.550 & 1.108 & 2.772 & -1.609 & 2.417 & -0.998 & 2.285 & -1.384 \\
\hline Bulandshahr & BDS & 1.498 & 1.924 & 0.882 & 0.608 & 2.395 & 0.255 & 2.392 & -0.115 \\
\hline Chandrapur & $\mathrm{CHD}$ & -0.849 & 0.746 & 0.687 & -0.024 & 0.459 & 0.228 & 0.571 & -0.567 \\
\hline Dewas & DEW & -0.155 & 0.898 & 0.189 & 0.138 & 1.230 & 0.093 & 1.121 & -0.740 \\
\hline Guwahati & GWH & 1.519 & -0.980 & 1.521 & 0.184 & -0.598 & -0.205 & -0.734 & -0.054 \\
\hline Howrah & HOW & -0.228 & 0.301 & -0.256 & -0.523 & -0.730 & -0.680 & -0.531 & -0.676 \\
\hline Jorapokhar & JPK & -0.374 & 1.823 & 0.081 & 1.042 & -0.035 & 0.488 & 0.935 & 0.677 \\
\hline Kanpur & KAN & 0.982 & -0.679 & -0.300 & 0.244 & 0.175 & 0.643 & 0.683 & 0.724 \\
\hline Kolkata & KOL & -0.344 & 0.006 & -0.448 & -0.212 & -0.831 & -0.602 & -0.932 & -0.539 \\
\hline Lucknow & LKW & 1.725 & -0.606 & 1.870 & -0.964 & 0.643 & 0.510 & 0.568 & -0.306 \\
\hline Mandikhera & MDK & -0.331 & 0.352 & -0.601 & 0.349 & -0.432 & 1.456 & -0.273 & 1.089 \\
\hline Mumbai & MUB & -1.072 & -0.570 & -0.716 & -0.688 & -0.853 & -0.596 & -0.915 & -0.336 \\
\hline Muzaffarpur & MFP & -0.130 & 1.648 & 0.118 & 1.298 & -0.207 & 0.407 & 0.095 & 0.886 \\
\hline Navi Mumbai & NMB & 0.330 & -0.360 & -0.476 & -0.216 & 0.177 & -0.818 & -0.594 & -0.236 \\
\hline Pali & PAL & 1.527 & -1.025 & 1.522 & 0.190 & -0.603 & -0.197 & -0.742 & -0.051 \\
\hline Patna & PTN & 0.335 & -0.836 & -0.313 & -0.655 & -0.730 & -0.245 & 0.054 & -0.367 \\
\hline Ratlam & RTM & 0.080 & 1.759 & 0.118 & -0.602 & 1.280 & -0.707 & 1.134 & -0.782 \\
\hline Satna & SAT & -1.146 & -1.582 & -1.352 & -0.407 & -0.621 & -0.103 & -0.877 & -0.513 \\
\hline Singrauli & SGU & 2.141 & -0.536 & 0.715 & 3.814 & 0.700 & 3.953 & 0.281 & 4.073 \\
\hline Solapur & SLP & -0.818 & -0.753 & -0.753 & -1.019 & -0.546 & -0.761 & -1.215 & 0.636 \\
\hline Talcher & $\mathrm{TLH}$ & -0.899 & 0.618 & 0.269 & -0.300 & 1.449 & -1.391 & 1.034 & 0.443 \\
\hline Tirupati & TUP & -1.421 & -0.690 & -1.055 & -0.650 & -0.619 & -0.786 & -0.823 & -1.041 \\
\hline Visakhapatnam & VSK & -0.196 & -1.220 & -1.127 & 0.601 & -1.603 & 0.698 & -1.499 & -0.258 \\
\hline
\end{tabular}

$78 \%, 45 \%, 47 \%, 34 \%$, and $8 \%$ decreases in $\mathrm{PM}_{2.5}, \mathrm{PM}_{10}, \mathrm{NO}_{2}$, $\mathrm{NH}_{3}, \mathrm{SO}_{2}, \mathrm{CO}$, and $\mathrm{O}_{3}$, respectively, were found during the three lockdown phases relative to prelockdown days (Table 6). The significant decrease in $\mathrm{NO}_{2}(78 \%)$ as compared with particulate matter (PM) could be due to its relation to the combustion of fossil fuels (coal, gas, and oil), especially as used in vehicles and off-road equipment during long-term lockdowns. Conversely, $\mathrm{PM}_{2.5}(49 \%)$ is the other prominently decreasing pollutants. The $\mathrm{SO}_{2}$ levels were reduced by $47 \%$ in the Kolkata-Howrah region. The largest source of $\mathrm{SO}_{2}$ in the atmosphere is the burning of fossil fuels by power plants and other industrial facilities. Importantly, notable decreases in concentrations of $\mathrm{NO}_{2}, \mathrm{PM}_{2.5}$, and $\mathrm{SO}_{2}$ were found for Fort William (94\%), Rabindra Bharati University (60\%), and Ghusuri (68\%) in the lockdown phases. For instance, as compared with an average decrease of $79 \%$ in the prelockdown to lockdown phase $\mathrm{I}, \mathrm{NO}_{2}$ concentration in prelockdown to lockdown phase II decreased by $87 \%$, indicating the direct effect of lockdown. A similar conclusion can also be derived for $\mathrm{PM}_{2.5}$ and $\mathrm{SO}_{2}$ in other stations. A slight increase in all seven criteria pollutant concentrations was observed in lockdown phase II as compared with lockdown phase I and lockdown phase III. This increase is in response to changes in the restrictions on power plants and coal-based powered energy for essential commodity production during lockdown phase III. Interestingly, an overall decrease in $\mathrm{O}_{3}(8 \%)$ was observed in lockdown phases as compared with prelockdown. The highest decreases are found at Victoria (42\%), with an increase also noted in Ghusuri (99\%) and Jadavpur (26\%) as compared with other stations. Ghusuri and Jadavpur reported an increase in $\mathrm{O}_{3}$ levels likely due to significant decreases of $\mathrm{NO}_{2}(85 \%$ and $77 \%$, respectively) relative to volatile organic compounds (VOCs) and premonsoon high temperatures. There was also a significant decrease in $\mathrm{CO}(34 \%)$ due to restrictions on outdoor transports or heavy machinery that burn fossil fuels. The maximum reduction was found in Victoria (49\%). Moreover, the maximum $\mathrm{NH}_{3}$ concentrations also decreased by $71 \%$ at Rabindra Bharati University monitor.

\section{b. Spatiotemporal pattern of $\mathrm{PM}_{2.5}, \mathrm{NO}_{2}$, and $\mathrm{SO}_{2}$}

The overall spatiotemporal pattern of air pollutants significantly varied between prelockdown to the different lockdown phases (Fig. 11). For phase I from 25 March to 14 April, concentrations for $\mathrm{PM}_{2.5}, \mathrm{NO}_{2}$, and $\mathrm{SO}_{2}$ were reduced by $23 \%$, $85 \%$, and $38 \%$. The second phase, from 15 April to 3 May, reduced $\mathrm{PM}_{2.5}, \mathrm{NO}_{2}$, and $\mathrm{SO}_{2}$ by $54 \%, 33 \%$, and $26 \%$, respectively. The third phase, from 4 to 17 May, substantially increased in $\mathrm{PM}_{2.5}$ and $\mathrm{NO}_{2}$ by $5 \%$ and $207 \%$, respectively, relative to phase II. $\mathrm{SO}_{2}$ significantly decreased by $77 \%$ as compared with lockdown phase I (38\%) and lockdown phase II (26\%). The lockdown rules demarcated cities in three zones-red, orange, and green-based on COVID-19 risk profiling during lockdown phase III. The GoI allowed some activities depending on the geographic risk profiles. These 


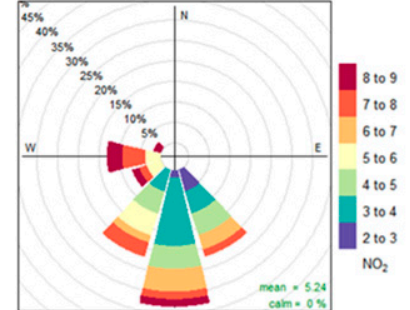

(a)

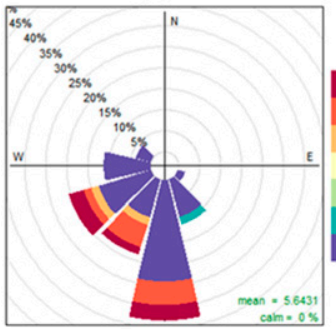

(e)

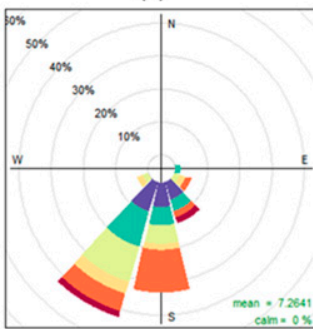

(i)

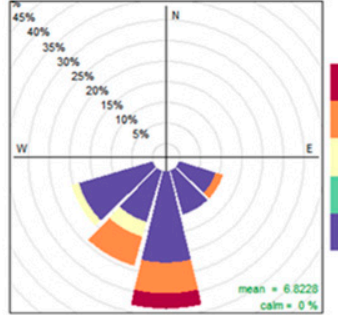

(b)

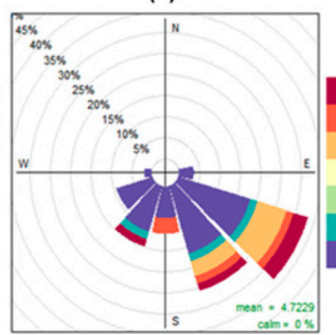

(f)

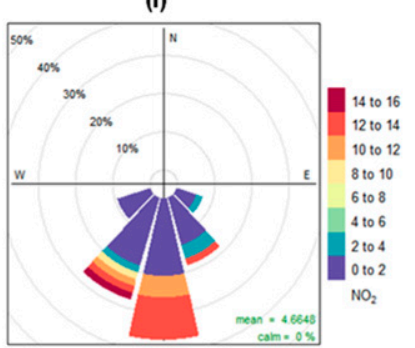

(j)

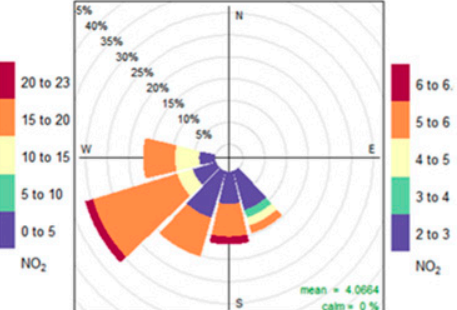

(c)

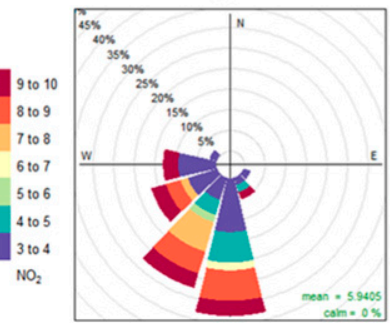

(g)

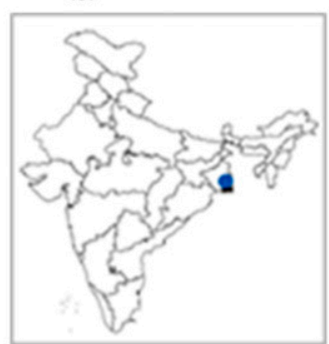

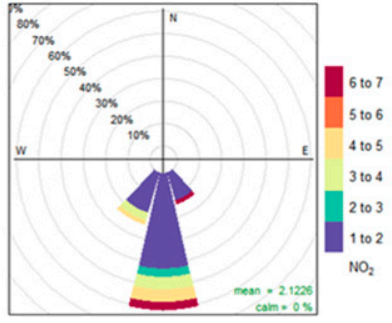

(d)

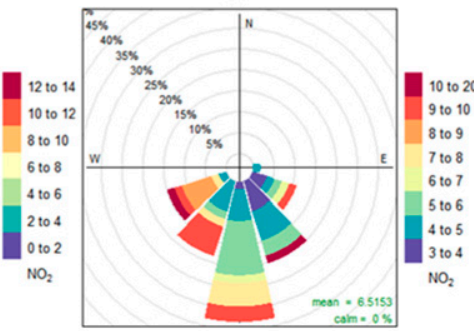

(h)

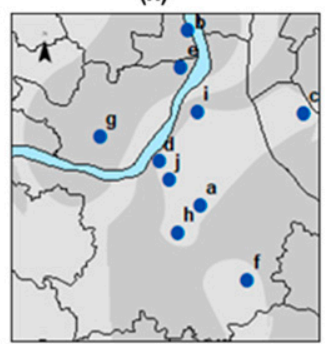

FIG. 9. Pollution rose plots of $\mathrm{NO}_{2}\left(\mu \mathrm{g} \mathrm{m}^{-3}\right)$ for air quality monitoring stations (3-10 $\mathrm{m}$ above ground level) in Kolkata-Howrah region. (a) Ballygunge, (b) Belurmath, (c) Bidhannagar, (d) Fort William, (e) Ghusuri, (f) Jadavpur, (g) Padmapukur, (h) Rabindra Sarobar, (i) Rabindra Bharati University, and (j) Victoria locations.

exemption-based activities show a direct response in terms of the increase in the level of $\mathrm{PM}_{2.5}$ and $\mathrm{NO}_{2}$ in the lockdown phase III for the Kolkata-Howrah region.

The station-based pollutant concentration differences (prelockdown to lockdown phase I, lockdown phase I to lockdown phase II, and lockdown phase II to lockdown phase III) were calculated based on the simple average of $\mathrm{PM}_{2.5}, \mathrm{NO}_{2}$, and $\mathrm{SO}_{2}$ for each station and shown in a spatial map (Fig. 11). The $\mathrm{PM}_{2.5}$ and $\mathrm{SO}_{2}$ levels are smallest from lockdown phase II to lockdown phase III as compared with from prelockdown to lockdown phase I and from lockdown phase I to lockdown phase II. The concentration of $\mathrm{NO}_{2}$ is least from lockdown phase I to lockdown phase II.

In summary, what emerges from this city-specific analysis is that there are a number of interactive and possible counterfactual outcomes related to unknown and localized increases in air pollution even when lockdown should have reduced them, likely because of feedback of local meteorology.

\section{Local versus large-scale impacts}

The variable results of lockdown on the air quality changes across the 91 cities considered led us to ask whether it would be possible to extract the influence of local versus the large-scale (meteorological) impact on the air quality. Wang et al. (2020), for instance, found that, for the lockdown in China, poor meteorological conditions led to a modest increase in air pollution levels. We identified pairs of a city with a nearby relatively pristine locale that can be studied in tandem (Table S2 in the online supplemental material). A total of 10 such pairs could be identified: two each in the north, south, east, west, and central part of the country. Most, if not all, of the air quality monitoring, is done within cities, and there was no remote background reference that could be found from in situ measurements. As a result, monthly averaged data for three months (March-May 2019 and March-May 2020) were analyzed from the daily MODIS satellite-based AOD and are shown in Fig. 12. The AOD grids covered the following 10 cities: Ahmedabad, Bengaluru, Bhopal, Bhubaneswar, Chennai, New Delhi, Jaipur, Kanpur, Kolkata, and Mumbai. The corresponding remote locations considered were 10 national forest/biosphere reserve (BR) sites: Nilgiri BR, Nanda Devi BR, Nokrek BR, Sundarban BR, Similipal BR, Dihang-Dibang, Pachmarhi BR, Khangchendzonga, Agasthyamalai BR, and AchanakmarAmarkantak BR. The assumption was that the AOD over these locations was less likely to be affected by the human activity in the city and represented the large-scale or background reference. The difference between the pairs is expected to 
(a)

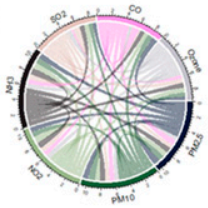

(c)

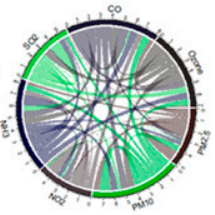

(e)

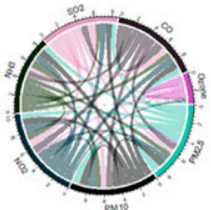

(g)

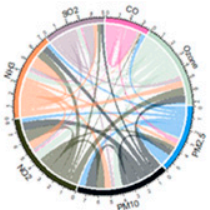

(i)

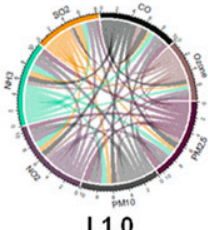

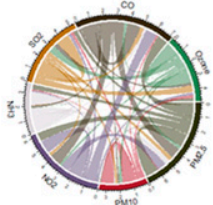
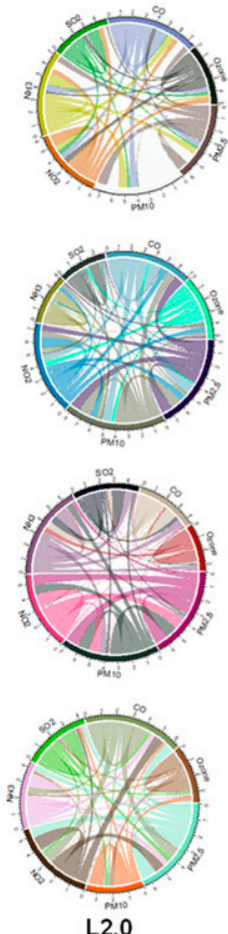
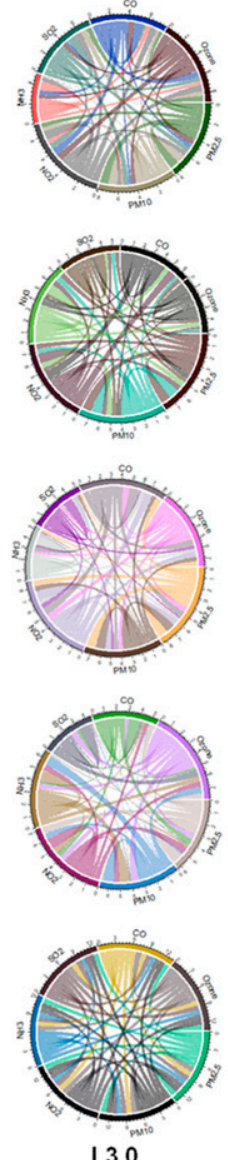

(b)
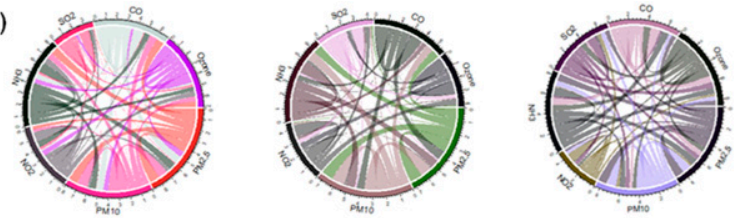

(d)
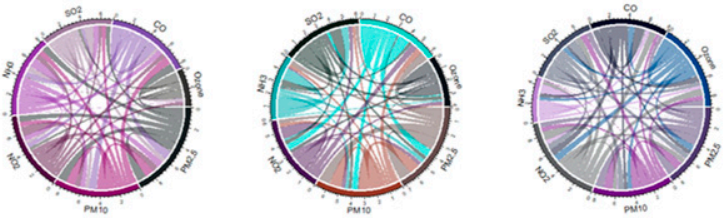

(f)
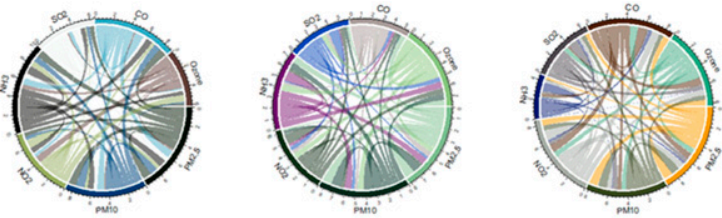

(h)
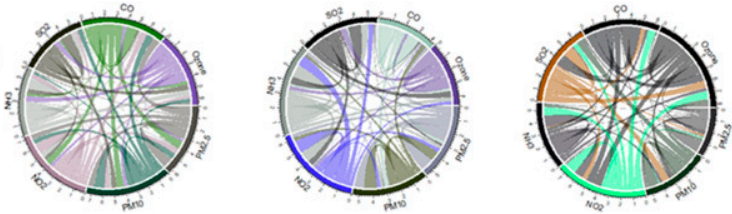

(j)
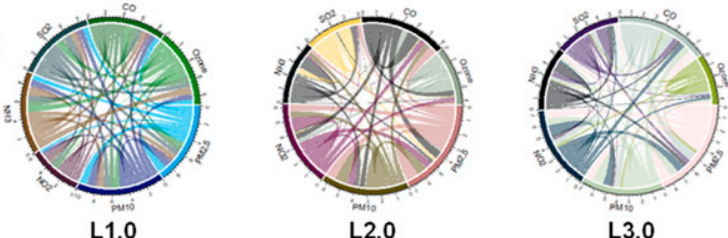

FIG. 10. Chord diagram illustrating the interrelationships between criteria pollutants for the Kolkata-Howrah region for (a) Ballygunge, (b) Bidhannagar, (c) Belurmath, (d) Fort William, (e) Ghusuri, (f) Jadavpur, (g) Padmapukur, (h) Rabindra Sarobar, (i) Rabindra Bharati University, and (j) Victoria air quality stations. Each panel contain three chord diagrams corresponding to three phases of the lockdown. Nodes in the chord diagram, indicated by partitions of the circumference, represent criteria pollutants $\mathrm{PM}_{2.5}$, $\mathrm{PM}_{10}, \mathrm{NO}_{2}, \mathrm{NH}_{3}, \mathrm{SO}_{2}, \mathrm{CO}$, and $\mathrm{O}_{3}$, beginning in the lower left and proceeding clockwise. The thickness of arcs between nodes is proportional to the strength of the connection.

provide a measure of local restrictions over the city relative to the changes due to large-scale meteorological changes that are not related to the restrictions in the local anthropogenic activities (Table 7).
The results shown in Fig. 13 indicate a clear impact of lockdown on the AOD levels in the city as compared with the reference forest sites. Mumbai, Bengaluru, Chennai, Bhopal, Ahmedabad, Jaipur, Kanpur, and Delhi saw AOD values that

TABLE 6. The changes (\%) in seven criteria air pollutants in three phases in lockdown as compared with before lockdown. Boldface type indicates maximum change in air pollutants as compared with other stations.

\begin{tabular}{|c|c|c|c|c|c|c|c|c|c|}
\hline Station & Premises & Code & $\mathrm{PM}_{2.5}$ & $\mathrm{PM}_{10}$ & $\mathrm{NO}_{2}$ & $\mathrm{NH}_{3}$ & $\mathrm{SO}_{2}$ & $\mathrm{CO}$ & $\mathrm{O}_{3}$ \\
\hline Ballygunge & Residential & BLG & -51 & -35 & -71 & -51 & -57 & -43 & -26 \\
\hline Bidhannagar & Commercial and residential & $\mathrm{BDN}$ & -38 & -44 & -67 & -34 & -41 & -9 & -38 \\
\hline Belur Math & Religious tourist & BLM & -45 & -52 & -84 & -52 & -43 & -37 & -42 \\
\hline Fort William & Open and green space & FTW & -51 & -39 & -94 & -59 & -45 & -36 & -14 \\
\hline Ghusuri & Industrial & GUS & -51 & -53 & -85 & -27 & -68 & -39 & +99 \\
\hline Jadavpur & Residential & JDP & -52 & -45 & -77 & -50 & -12 & -29 & +28 \\
\hline Padmapukur & Residential & PMP & -48 & -42 & -73 & -58 & -43 & -14 & -16 \\
\hline RabindraSarabor & Green space & RBS & -54 & -43 & -57 & -31 & -54 & -36 & -22 \\
\hline Rabindra Bharati University & Residential & RBU & -60 & -49 & -81 & -71 & -65 & -42 & -3 \\
\hline Victoria & Green space & VCT & -45 & -51 & -88 & -15 & -43 & -49 & -42 \\
\hline Overall changes $(\%)$ & & - & -49 & -45 & -78 & -45 & -47 & -34 & -8 \\
\hline
\end{tabular}




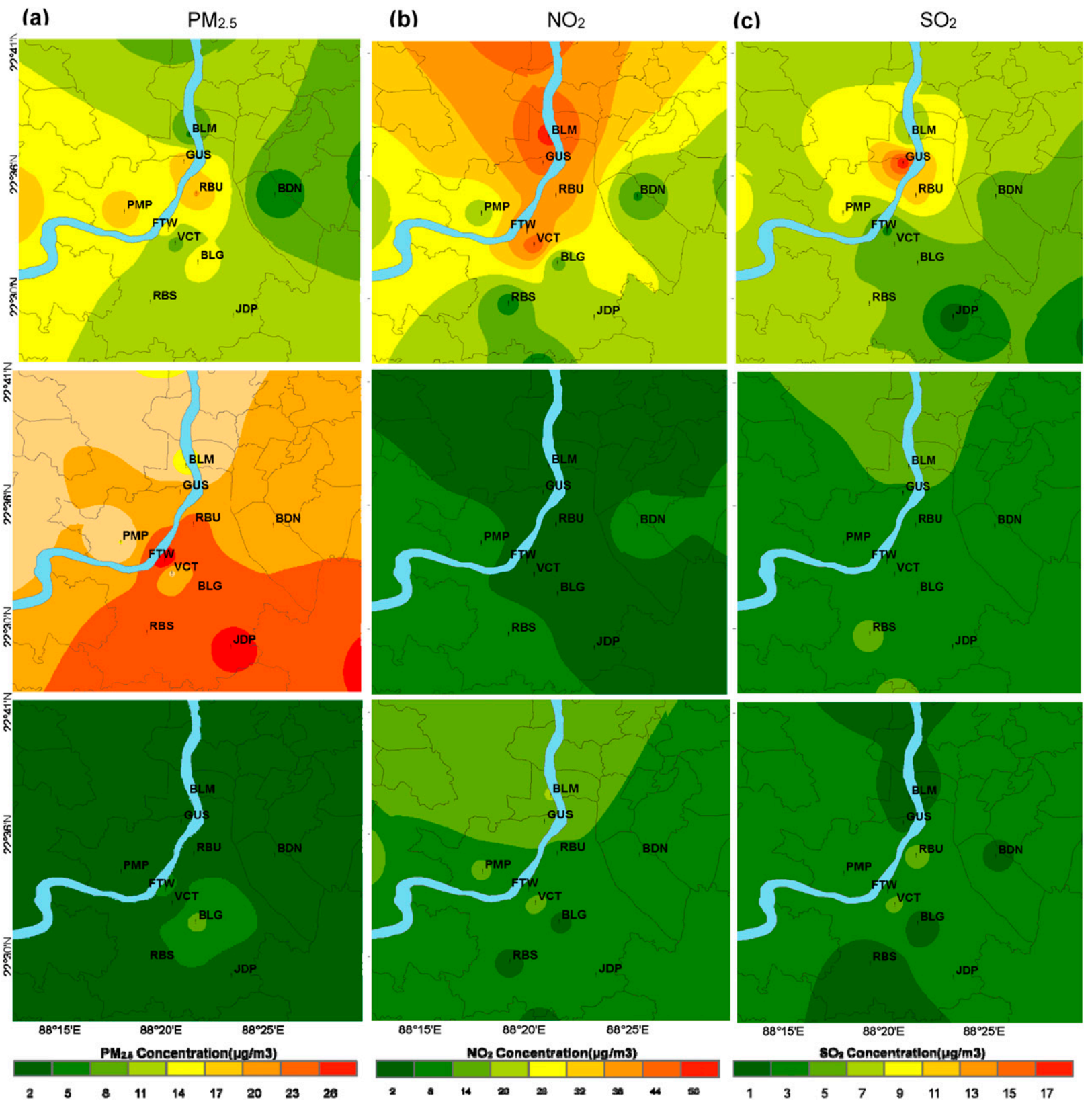

FIG. 11. Spatial maps of average concentration of (a) $\mathrm{PM}_{2.5}$, (b) $\mathrm{NO}_{2}$, and (c) $\mathrm{SO}_{2}$, for the Kolkata-Howrah region. These plots demonstrate the interdifference map of different lockdown phases: (top) Prelockdown minus lockdown phase I, (middle) lockdown phase I minus phase II, and (bottom) lockdown phase II minus phase III.

are between $40 \%$ and $60 \%$ of the levels noted for a similar period in the previous year. Interestingly, a similar reduction could be noted in the reference forest/BR sites, indicative of a much broader improvement in the regional air quality (i.e., not just for the city scale). On the other hand, the AOD concentrations were typically high in the cities and noncity (forest) sites of eastern India (Kolkata, Bhubaneswar, Nokrek National Park, Sunderban BR, and Similipal BR). This is likely due to temperature increases and strong westerly winds, emissions and transformation, and possible particulate transport from the Thar Desert and Arabian Peninsula as compared with other parts of the country during premonsoon months (e.g., Kumar et al. 2020).

The AOD levels were high in Bhubaneswar, Delhi, Kanpur, Kolkata, Mumbai, and Jaipur relative to nearby noncity sites both before and after lockdown periods. The magnitude of change in AOD levels in forested sites is indistinguishable in lockdown and prelockdown phases during the study period. The results of vehicular emission, indicating a significant restriction during the lockdown, show a substantially decreased 


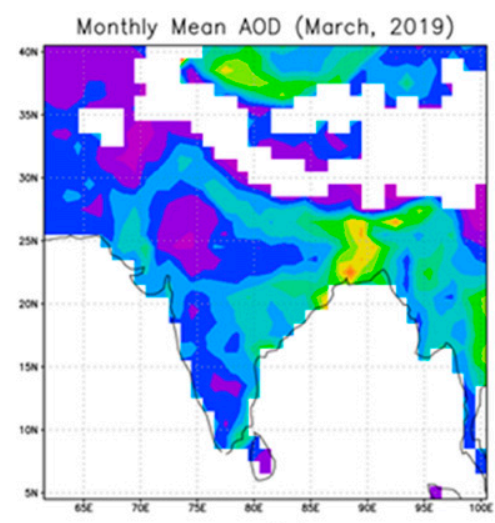

(a)

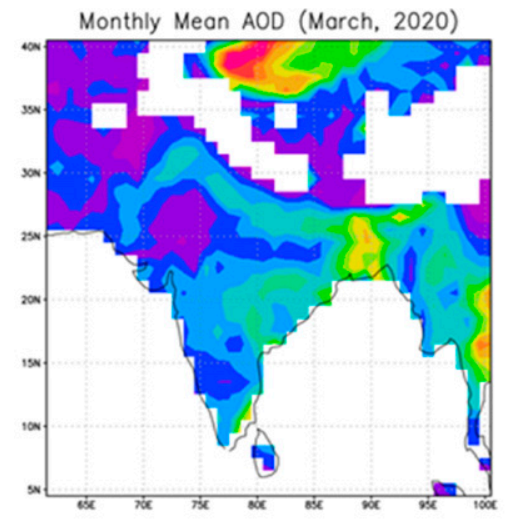

(a')

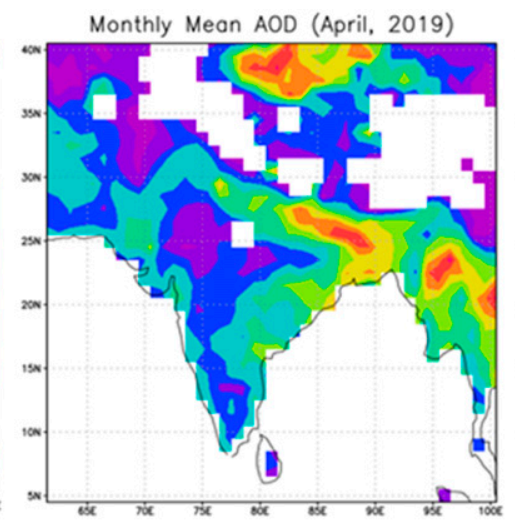

(b)

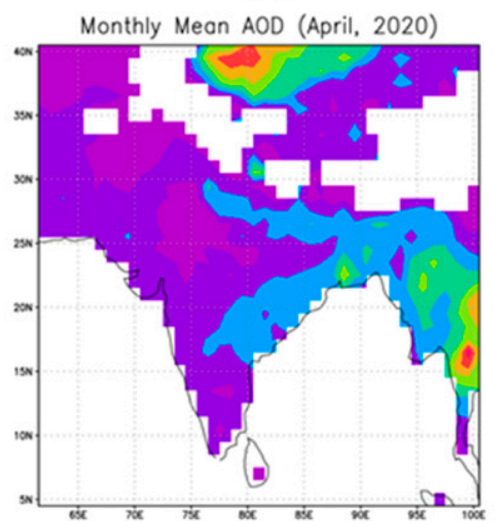

(b')

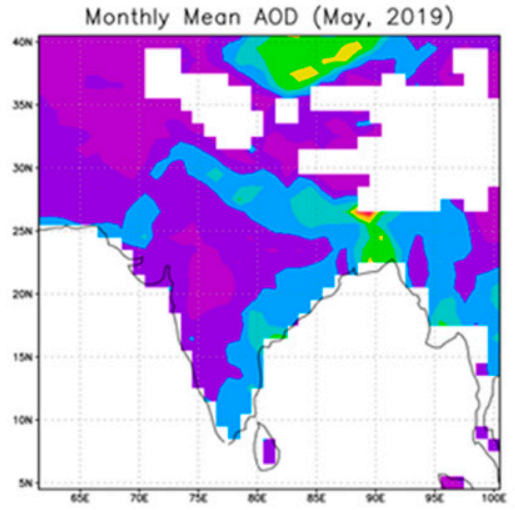

(c)

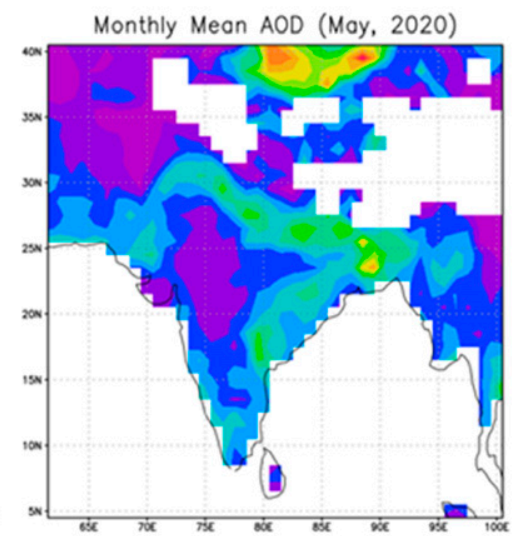

(c')

FIG. 12. Monthly mean, satellite-derived MODIS aerosol optical depth over the Indian subcontinent for (a),(a') March; (b),(b') April; and (c), (c') May of (top) 2019 and (bottom) 2020.

pollutant level over the city $(60 \%)$ as well as improved ambient air quality over the city. Thus, the selected cities show a significant reduction in the AOD levels due to local restricted human activities, as expected, and an insignificant change could be attributed to the large-scale impact. A similar aspect was noted in a recent study by Sathe et al. (2021).

The differences in monthly mean AOD patterns over different regions of the country also suggest that the distribution of aerosol emissions and burdens are quite different across the urban regions.

The positive anomaly in the country's eastern region between urban centers and forest sites needs to be examined further because pairwise comparisons are often assumed as representative of the broader context, and this may not be the effect of vehicular emission. In both references of the studies (urban centers and forest sites), to some extent, AOD level decreases are significant during the lockdown as compared with prelockdown.

\section{Conclusions}

This study examined the changes in air pollution across 91 cities in India caused by the COVID-19 lockdown in 2020. The lockdown in India was in three stages, with the restrictions imposed being modified depending upon conditions that existed during each stage. The AQI and pollutant concentrations during the three phases of lockdown was compared with both the corresponding values for the seven days preceding the lockdown (prelockdown phase) and for the same days of the year from 2019. Correlation of AQI computed using 2019 and 2020 paired values shows the values to be statistically insignificant for most stations during the prelockdown time period. However, during the three phases of the lockdown, most stations show a statistically significant correlation with $37 \%$ or more exhibiting negative correlation.

Of the 91 stations analyzed, 27 stations showed statistically negative significant trends and majority of these stations are found to be located in the vicinity of the major or minor industrial regions. We compared the AQI and criteria pollutant concentrations of these cities during the lockdown with corresponding values during the same days in 2019. The spatial variability of this comparison was analyzed by regionally grouping the stations with statistically significant trends. This analysis showed that northern regions to be most impacted during the first two phases of the lockdown while the southern region was most affected during the third phase. The 
TABLE 7. The magnitude of mean AOD differences between city and nearby forest sites in selected cities.

\begin{tabular}{|c|c|c|c|c|c|c|c|c|c|c|}
\hline \multirow[b]{2}{*}{ Cities } & \multirow{2}{*}{$\begin{array}{l}\text { Height } \\
\text { MSL } \\
(\mathrm{m})\end{array}$} & \multirow{2}{*}{$\begin{array}{c}\text { Nearby } \\
\text { forest }\end{array}$} & \multirow{2}{*}{$\begin{array}{l}\text { Height } \\
\text { MSL } \\
(\mathrm{m})\end{array}$} & \multirow{2}{*}{$\begin{array}{l}\text { Distance } \\
\text { from } \\
\text { city }(\mathrm{km})\end{array}$} & \multicolumn{3}{|c|}{ Before lockdown } & \multicolumn{3}{|c|}{ Lockdown } \\
\hline & & & & & AOD0319 & AOD0419 & AOD0519 & AOD0320 & AOD0420 & AOD0520 \\
\hline Ahmedabad & 53 & Pachmai BR & 1067 & 780 & 0.078 & 0.090 & 0.120 & -0.070 & 0.092 & -0.026 \\
\hline Bangalore & 920 & Nilgiri BR & 1100 & 190 & 0.039 & 0.055 & 0.052 & -0.093 & 0.000 & 0.006 \\
\hline Bhopal & 527 & Pachmai BR & 1067 & 207 & 0.024 & 0.038 & 0.017 & -0.024 & 0.033 & -0.039 \\
\hline Bhubaneswar & 58 & Similpal BR & 900 & 162 & 0.124 & 0.028 & 0.030 & 0.166 & 0.045 & 0.048 \\
\hline Chennai & 6.7 & Nilgiri BR & 1100 & 370 & 0.229 & 0.090 & 0.115 & 0.057 & -0.009 & -0.126 \\
\hline Delhi & 215 & $\begin{array}{l}\text { Nanda } \\
\text { Devi BR }\end{array}$ & 3500 & 510 & 0.444 & 0.416 & 0.479 & 0.423 & 0.404 & 0.459 \\
\hline Jaipur & 431 & $\begin{array}{l}\text { Nanda } \\
\text { Devi BR }\end{array}$ & 3500 & 760 & 0.125 & 0.100 & 0.131 & 0.124 & 0.068 & 0.123 \\
\hline Kanpur & 126 & $\begin{array}{l}\text { Nanda } \\
\text { Devi BR }\end{array}$ & 3500 & 615 & 0.394 & 0.348 & 0.375 & 0.415 & 0.352 & 0.438 \\
\hline Kolkata & 9.14 & $\begin{array}{l}\text { Sunderban } \\
\text { BR }\end{array}$ & 2 & 105 & 0.331 & 0.121 & 0.148 & 0.311 & 0.349 & 0.230 \\
\hline Mumbai & 14 & Pachmai BR & 1067 & 910 & 0.122 & 0.189 & 0.173 & 0.012 & 0.151 & 0.116 \\
\hline
\end{tabular}

northeastern region is least affected during all phases of the lockdown. The eastern region is also less affected than other regions and shows a consistent increase in $\mathrm{O}_{3}$ during the lockdown. This is likely due to the reduction in $\mathrm{PM}\left(\mathrm{PM}_{2.5}\right.$ and $\left.\mathrm{PM}_{10}\right)$ as well as $\mathrm{NO}_{2}$ and VOCs. The pattern of decrease in $\mathrm{PM}_{2.5}$ and $\mathrm{NO}_{2}$ accompanied by an increase in $\mathrm{O}_{3}$ concentrations over Indian cities have also been reported for cities in northern China, western Europe, Southeast Asia, and the
United States. Nationwide average values of AQI, $\mathrm{PM}_{2.5}$, $\mathrm{PM}_{10}, \mathrm{NO}_{2}, \mathrm{O}_{3}, \mathrm{SO}_{2}, \mathrm{NH}_{3}$, and $\mathrm{CO}$ decreased by $33 \%, 36 \%$, $40 \%, 58 \%, 5 \%, 25 \%, 28 \%$, and $60 \%$ during lockdown when compared with values for corresponding days in 2019. These reductions can be considered lower bounds of air quality burdens or the background levels associated with transportation and industrial sectors. We also compared the AQI and criteria pollutant concentrations during the lockdown phases with
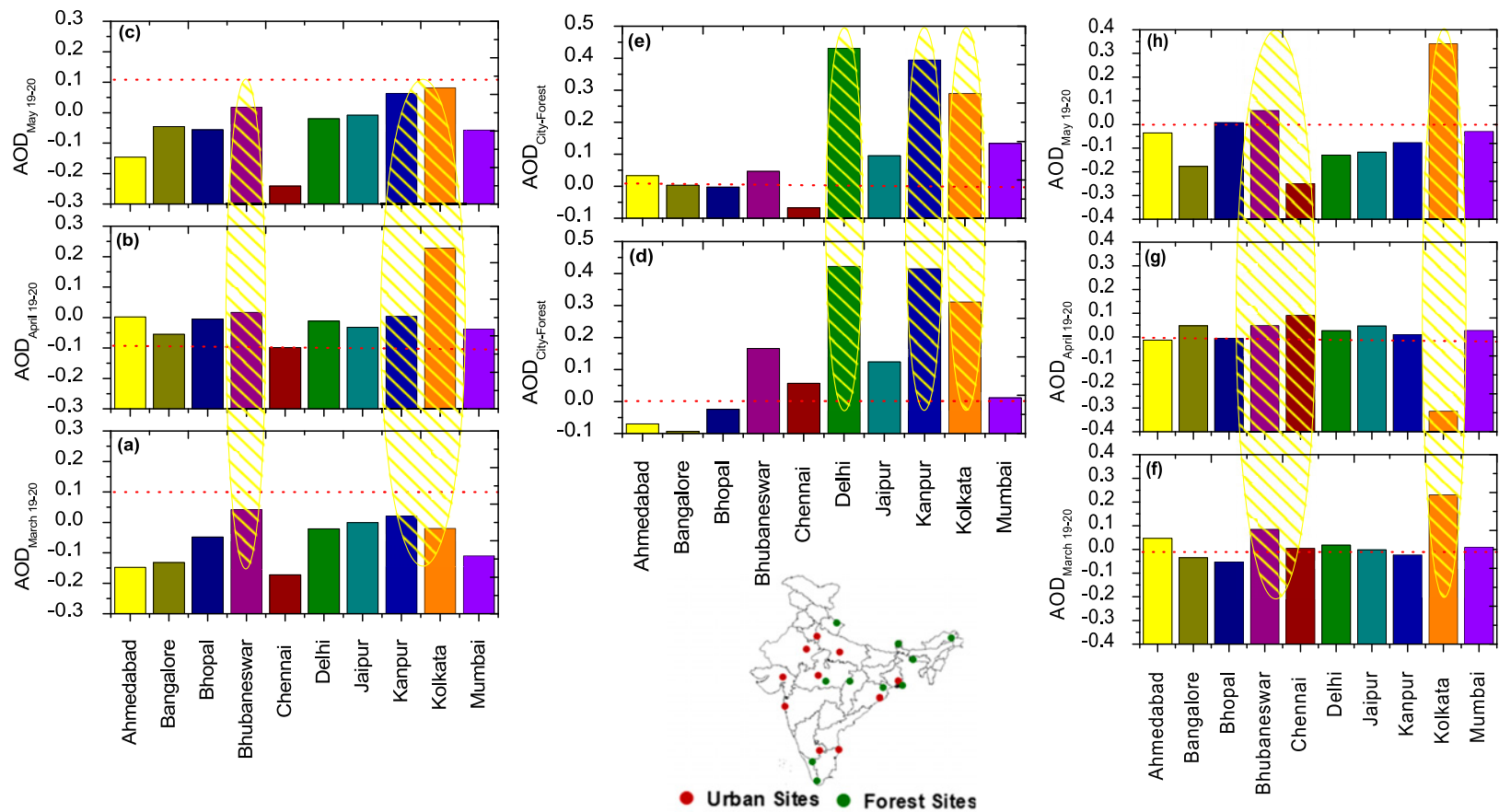

FIG. 13. The large-scale impacts of restricted human activities across India: differences of the anomaly (from city to forest) of monthly average AOD during (a) March, (b) April, and (c) May (2019 - 2020) over cities, the AOD difference between city and forest during (d) prelockdown (2020) and (e) lockdown period (2020), and difference for each city of monthly average AOD during (f) March, (g) April, and (h) May (2019 - 20) over cities. Locations of the urban and forest sites are shown in the map inset using red and green circles, respectively. 
corresponding values during the prelockdown period, which also show significant decreases. Overall, 43 of the 91 cities experienced an improvement in air quality during the second phase as opposed to 27 and 20 cities during phase I and phase III, respectively.

Anomalous behavior over the eastern region, coupled with additional analysis of Kolkata-Howrah region suggests that regional differences in meteorology and societal response to lockdown could be responsible for differing behavior in these areas. Further, analysis of satellite-derived aerosol column burden shows that the effect of lockdown on $\mathrm{PM}_{2.5}$ differed depending on the region, with the reductions being localized in some areas (e.g., Kolkata) and broadscale (e.g., Delhi, northern India) in other areas.

The above findings have environmental policy implications because they provide estimates of air quality impacts of industrial and transportation sectors rooted in observations rather than models. Further analysis considering the differing nature of restrictions imposed during the three phases could better isolate human-activity-based contributions to air quality. For example, while the lockdown in Delhi (one of the most highly polluted cities in the world) yielded a reduction in criteria pollutants such as $\mathrm{PM}_{2.5}, \mathrm{NO}_{2}$, and $\mathrm{SO}_{2}$, it did not result in a statistically significant decreasing trend in AQI for the study period. Such patterns could indicate the level of adherence by local populations to COVID-19 restrictions imposed by the GoI and the long-range transport aspects that continue to affect this region (Kanawade et al. 2020).

Acknowledgments. This research was made possible with air quality and meteorological data support from the Central Pollution Control Board (CPCB), Ministry of Environment, Forest and Climate Change (MoEFCC), government of India. Author Dev Niyogi acknowledges support from the U.S. National Science Foundation, NASA Interdisciplinary Sciences (IDS) program, and the University of Texas at Austin. The authors declare no conflicts of interest.

\section{REFERENCES}

Aneja, V. P., C. S. Claiborn, Z. Li, and A. Murthy, 1994: Trends, seasonal variations, and analysis of high-elevation surface nitric acid, ozone, and hydrogen peroxide. Atmos. Environ., 28, 1781-1790, https://doi.org/10.1016/1352-2310(94)90140-6.

Azid, A., and Coauthors, 2014: Prediction of the level of air pollution using principal component analysis and artificial neural network techniques: A case study in Malaysia. Water Air Soil Pollut., 225, 2063, https://doi.org/10.1007/s11270-014-2063-1.

Balakrishnan, K., and Coauthors, 2019: The impact of air pollution on deaths, disease burden, and life expectancy across the states of India: The Global Burden of Disease Study 2017. Lancet Planet. Health, 3, e26-e39, https://doi.org/10.1016/S25425196(18)30261-4.

Bartuccelli, M. V., J. H. Deane, G. Gentile, and L. Marsh, 2006: Invariant sets for the varactor equation. Proc. Roy. Soc. Math. Phys. Eng. Sci., 462, 439-457, https://doi.org/10.1098/RSPA. 2005.1569.

Chen, S., and D. E. Bloom, 2019: The macroeconomic burden of noncommunicable diseases associated with air pollution in
China. PLOS ONE, 14, e0215663, https://doi.org/10.1371/ journal.pone.0215663.

Collier, S., and Coauthors, 2018: Influence of emissions and aqueous processing on particles containing black carbon in a polluted urban environment: Insights from a soot particleaerosol mass spectrometer. J. Geophys. Res. Atmos., 123, 6648-6666. https://doi.org/10.1002/2017JD027851.

CPCB, 2014: National air quality index. Ministry of Environment Forest and Climate Change Central Pollution Control Board Doc., accessed 20 July 2020, 58 pp., https://cpcb.nic.in/ displaypdf.php?id=bmF0aW9uYWwtYWlyLXF1YWxpdHkta W5kZXgvRk1OQUwtUkVQT1JUX0FRSV8ucGRm.

Dziuban, C. D., and E. C. Shirkey, 1974: When is a correlation matrix appropriate for factor analysis? Some decision rules. Psychol. Bull., 81, 358-361, https://doi.org/10.1037/h0036316.

Emami, F., M. Masiol, and P. K. Hopke, 2018: Air pollution at Rochester, NY: Long-term trends and multivariate analysis of upwind $\mathrm{SO}_{2}$ source impacts. Sci. Total Environ., 612, 15061515, https://doi.org/10.1016/j.scitotenv.2017.09.026.

Garaga, R., S. K. Sahu, and S. H. Kota, 2018: A review of air quality modeling studies in India: Local and regional scale. Curr. Pollut. Rep., 4, 59-73, https://doi.org/10.1007/s40726-018-0081-0.

Ghude, S. D., and Coauthors, 2016: Premature mortality in India due to $\mathrm{PM}_{2.5}$ and ozone exposure. Geophys. Res. Lett., $\mathbf{4 3 ,}$ 4650-4658, https://doi.org/10.1002/2016GL068949.

Gilbert, R. O., 1987: Statistical Methods for Environmental Pollution Monitoring. John Wiley and Sons, 320 pp.

Gray, E., S. Gilardoni, D. Baldocchi, B. C. McDonald, M. C. Facchini, and A. H. Goldstein, 2019: Impact of air pollution controls on radiation fog frequency in the Central Valley of California. J. Geophys. Res. Atmos., 124, 5889-5905, https:// doi.org/10.1029/2018JD029419.

Hadeed, S. J., M. K. O'Rourke, J. L. Burgess, R. B. Harris, and R. A. Canales, 2020: Imputation methods for addressing missing data in short-term monitoring of air pollutants. Sci. Total Environ., 730, 139140, https://doi.org/10.1016/j.scitotenv. 2020.139140.

Hollander, M., and D. A. Wolfe, 1973: Nonparametric Statistical Methods. John Wiley and Sons, 503 pp.

Imtiaz, S. A., and S. L. Shah, 2008: Treatment of missing values in process data analysis. Can. J. Chem. Eng., 86, 838-858.

India Meteorological Department, 2020: Public weather bulletin. Government of India Bull., 3 pp., https://mausam.imd.gov.in/ backend/assets/press_release_pdf/PWB_20_03_2020_.pdf.

Kaiser, H. F., 1958: The varimax criterion for analytic rotation in factor analysis. Psychometrika, 23, 187-200, https://doi.org/ 10.1007/BF02289233.

Kanawade, V. P., and Coauthors, 2020: What caused severe air pollution episode of November 2016 in New Delhi? Atmos. Environ., 222, 117125, https://doi.org/10.1016/j.atmosenv.2019. 117125.

Kumar, A., T. K. Sankar, S. S. Sethi, and B. Ambade, 2020: Characteristics, toxicity, source identification and seasonal variation of atmospheric polycyclic aromatic hydrocarbons over east India. Environ. Sci. Pollut. Res. Int., 27, 678-690, https://doi.org/10.1007/s11356-019-06882-5.

Lancet, T., 2020: India under COVID-19 lockdown. Lancet, 395, 1315, https://doi.org/10.1016/S0140-6736(20)30938-7.

Lang, P. E., D. C. Carslaw, and S. J. Moller, 2019: A trend analysis approach for air quality network data. Atmos. Environ. X, 2, 100030, https://doi.org/10.1016/j.aeaoa.2019.100030.

Li, C., and Coauthors, 2007: In situ measurements of trace gases and aerosol optical properties at a rural site in northern China 
during East Asian Study of Tropospheric Aerosols: An International Regional Experiment 2005. J. Geophys. Res., 112, D22S04, https://doi.org/10.1029/2006JD007592.

Little, R. J., and D. B. Rubin, 2002: Bayes and multiple imputation. Statistical Analysis with Missing Data, John Wiley and Sons, 200-220.

Liu, H., Z. Duan, and C. Chen, 2019: A hybrid framework for forecasting PM2.5 concentrations using multi-step deterministic and probabilistic strategy. Air Qual. Atmos. Health, 12, 785-795, https://doi.org/10.1007/s11869-019-00695-8.

McNeil, V. H., M. E. Cox, and M. Preda, 2005: Assessment of chemical water types and their spatial variation using multistage cluster analysis, Queensland, Australia. J. Hydrol., 310, 181-200, https://doi.org/10.1016/j.jhydrol.2004.12.014.

Niyogi, D., H. I. Chang, F. Chen, L. Gu, A. Kumar, S. Menon, and R. A. Pielke, 2007: Potential impacts of aerosol-landatmosphere interactions on the Indian monsoonal rainfall characteristics. Nat. Hazards, 42, 345-359, https://doi.org/ 10.1007/s11069-006-9085-y.

Parveen, R., and A. Ahmad, 2020: Public behavior in reducing urban air pollution: An application of the theory of planned behavior in Lahore. Environ. Sci. Pollut. Res. Int., 27, 1781517830, https://doi.org/10.1007/s11356-020-08235-z.

Picheta, R., 2020: People in India can see the Himalayas for the first time in 'decades,' as the lockdown eases air pollution. CNN, accessed 18 August 2020, https://www.cnn.com/travel/article/ himalayas-visible-lockdown-india-scli-intl/index.html.

Ravindra, K., T. Singh, V. Pandey, and S. Mor, 2020: Air pollution trend in Chandigarh city situated in Indo-Gangetic Plains: Understanding seasonality and impact of mitigation strategies. Sci. Total Environ., 729, 138717, https://doi.org/10.1016/j.scitotenv. 2020.138717.

Sathe, Y., P. Gupta, M. Bawase, L. Lamsal, F. Patadia, and S. Thipse, 2021: Surface and satellite observations of air pollution in India during COVID-19 lockdown: Implication to air quality. Sustainable Cities Soc., 66, 102688, https://doi.org/ 10.1016/j.scs.2020.102688.

Schafer, J. L., 1999: Multiple imputation: A primer. Stat. Methods Med. Res., 8, 3-15, https://doi.org/10.1177/ 096228029900800102.

Sen, P. K., 1968: Estimates of the regression coefficient based on Kendall's tau. J. Amer. Stat. Assoc., 63, 1379-1389, https:// doi.org/10.1080/01621459.1968.10480934.

Taghavi-Shahri, S. M., A. Fassò, B. Mahaki, and H. Amini, 2020: Concurrent spatiotemporal daily land use regression modeling and missing data imputation of fine particulate matter using distributed space-time expectation maximization. Atmos. Environ., 224, 117202, https://doi.org/10.1016/J.ATMOSENV.2019.117202.

Theil, H., 1950: A rank-invariant method of linear and polynomial regression analysis (parts 1-3). Ned. Akad. Wet. Proc., 53A, 1397-1412.

Wang, P., K. Chen, S. Zhu, P. Wang, and H. Zhang, 2020: Severe air pollution events not avoided by reduced anthropogenic activities during COVID-19 outbreak. Resour. Conserv. Recycl., 158, 104814, https://doi.org/10.1016/j.resconrec.2020.104814.

West Bengal Pollution Control Board, 2020: Air Quality Information System. AQI Bulletin, accessed 10 July 2020, http://emis.wbpcb.gov.in/airquality/aqiBulletin.jsp.

Xu, Z., Z. Liu, G. Fu, and Y. Chen, 2010: Trends of major hydroclimatic variables in the Tarim River basin during the past 50 years. J. Arid Environ., 74, 256-267, https://doi.org/10.1016/ j.jaridenv.2009.08.014.

Yu, T. Y., and L. F. W. Chang, 2000: Selection of the scenarios of ozone pollution at southern Taiwan area utilizing principal component analysis. Atmos. Environ., 34, 4499-4509, https:// doi.org/10.1016/S1352-2310(00)00112-6.

Yuan, Y. C., 2016: Multiple imputation for missing data: Concepts and new development (version 9.0). SAS Institute Doc., 13 pp., https://support.sas.com/rnd/app/stat/papers/ multipleimputation.pdf. 